\title{
Near-Zero NOx Combustion Technology for ATS Mercury 50 Gas Turbine
}

\author{
Final Report \\ December 2004
}

\author{
Submitted By: \\ Solar Turbines Incorporated \\ 2200 Pacific Highway, \\ P.O. Box 85376 \\ San Diego, CA 92186-5376
}

Agreement Number: DE-FC02-00CH11055

Solar Contact: Kenneth O Smith

Phone: (619) 5445539

E-mail: smith_kenneth_o@solarturbines.com 


\section{PART I: STI PRODUCT DESCRIPTION}

(To be completed by Recipient/Contractor

\section{A. STI Product Identifiers}

1. REPORT/PRODUCT NUMBER(s)

NONE

2. DOE AWARD/CONTRACT NUMBER(s)

DE-FE02-00CH11055

3. OTHER IDENTIFYING NUMBER(s)

\section{B. Recipient/Contractor}

Solar Turbines Incorporated

C. STI Product Title

Near Zero NOx Combustor for ATS Mercury 50 Gas Turbine

D. Author(s)

Kenneth O. Smith

E-mail Address(es):

Smith ken_o@solarturbines.com

E. STI Product Issue Date/Date of Publication $12 / 31 / 04$

$(\mathrm{mm} / \mathrm{dd} / \mathrm{yyyy})$

\section{F. STI Product Type (Select only one)}

$\mathbf{X}$ 1. TECHNICAL REPORT

x Final $\square$ Other (specify)

2. CONFERENCE PAPER/PROCEEDINGS

Conference Information (title, location, dates)

3. JOURNAL ARTICLE
a. TYPE: $\square$ Announcement Citation Only $\square$ Preprint $\square$ Postprint
b. JOURNAL NAME

c. VOLUME

d. ISSUE

e. SERIAL IDENTIFIER (e.g. ISSN or CODEN)

OTHER, SPECIFY

G. STI Product Reporting Period (mm/dd/yyyy)

$10 / 29 / 00$

Thru

$12 / 31 / 04$

\section{H. Sponsoring DOE Program Office}

EERE- Distributed Energy

I. Subject Categories (list primary one first)

24,03,29,32,42

Keywords

Gas turbine combustion, catalytic combustion, emissions reduction

J. Description/Abstract

Preliminary test results of an ultra-low NOx gas turbine combustion technology using rich catalytic combustion are presented.

K. Intellectual Property/Distribution Limitations

(must select at least one; if uncertain contact your Contracting Officer (CO))

$\mathbf{X}$ 1. UNLIMITED ANNOUNCEMENT (available to U.S. and non-U.S. public; the Government assumes no liability for disclosure of such data)

2. COPYRIGHTED MATERIAL: Are there any restrictions based on copyright? $\square$ Yes $\square$ No If yes, list the restrictions as retained in your contract

3. PATENTABLE MATERIAL: THERE IS PATENTABLE MATERIAL IN THE DOCUMENT INVENTION DISLOSURE SUBMITTED TO DOE: DOE Docket Number: S-

(Sections are marked as restricted distribution pursuant to 35 USC 205)

4. PROTECTED DATA: $\square$ CRADA $\square$ Other If other, specify

Release date ( $\mathrm{mm} / \mathrm{dd} / \mathrm{yyyy})$

5. SMALL BUSINESS INNOVATION RESEARCH (SBIR) DATA

Release date (Required, (No more than 4 years from date listed in part 1.E above)

6. SMALL BUSINESS TRANSFER (STTR) DATA

Release date (Required,

No more than 4 years from date listed in part 1.E above)

7. OFFICE OF NUCLEAR ENERGY APPLIED TECHNOLOGY

L. Recipient/Contractor Point of Contact

Kenneth O. Smith, Mgr. Advanced Combustion

Name and/or Position

Smith ken_o@solarturbines.com (619) 5445539

E-mail

Phone

Solar Turbines Incorporated

Organization 


\section{PART II: STI PRODUCT MEDIA/FORMAT and LOCATION/TRANSMISSION}

(To be completed by Recipient/Contractor)

\section{A. Media/Format Information:}

1. MEDIUM OF STI PRODUCT IS:

X Electronic Document $\square$ Computer medium

$\square$ Audiovisual material $\square$ Paper $\square$ No full-text

2. SIZE OF STI PRODUCT 50 pages

3. SPECIFY FILE FORMAT OF ELECTRONIC DOCUMENT BEING TRANSMITTED, INDICATE:

$\square$ SGML $\square$ HTML $\square$ XML $\square$ PDF Normal $\square$ PDF Image

$\square$ WP-Indicate Version (5.0 or greater)

Platform/operating system

$\square$ MS-Indicate Version (5.0 or greater)

Platform/operating system

$\square$ Postscript

4. IF COMPUTER MEDIUM OR AUDIOVISUAL

a. Quantity/type (specify)

b. Machine compatibility (specify)

c. Other information about product format a user needs to know:

B. Transmission Information:

STI PRODUCT IS BEING TRANSMITTED:

$X$ 1. Electronic via Elink

2. Via mail or shipment to address indicated in award document (Paper products, CD-ROM, diskettes, videocassettes, et.)

$\mathbf{X}$ 2a. Information product file name (of transmitted electronic format)

Near Zero NOx Combustion Technology - Final

\section{PART III: STI PRODUCT REVIEW/RELEASE INFORMATION}

(To be completed by DOE)

\section{A. STI Product Reporting Requirement Review: \\ $\mathbf{X}$ 1. THIS DELIVERABLE COMPLETES ALL REQUIRED DELIVERABLES FOR THIS AWARD \\ $\square$ 2. THIS DELIVERABLE FULFILLS A TECHNICAL REPORTING REQUIREMENT, BUT SHOULD NOT BE DISSEMINATED BEYOND DOE.}

\section{B. DOE Releasing Official}

$\square$ 1. I VERIFY THAT ALL NECESSARY REVIEWS HAVE BEEN COMPLETED AS DESCRIBED IN DOE G 241.1-1A, PART II, SECTION 3.0 AND THAT THE STI PRODUCT SHOULD BE RELEASED IN ACCORDANCE WITH THE INTELLECTUAL PROPERTY/DISTRIBUTION LIMITATION ABOVE.

Released by (name)

Date $(\mathrm{mm} / \mathrm{dd} / \mathrm{yyyy})$

E-mail

Phone 


\section{Disclaimer}

This report was prepared as an account of work sponsored by an agency of the United States Government. Neither the United States Government nor any agency thereof, nor any of their employees, makes any warranty, express or implied, or assumes any legal liability or responsibility for the accuracy, completeness, or usefulness of any information, apparatus, product, or process disclosed, or represents that its use would not infringe privately owned rights. Reference herein to any specific commercial product, process, or service by trade name, trademark, manufacturer, or otherwise does not necessarily constitute or imply its endorsement, recommendation, or favoring by the United States Government or any agency thereof. The views and the opinions of the

authors expressed herein do not necessarily state or reflect those of the United States Government or any agency thereof. 


\section{Table of Contents}

Disclaimer $\quad$ ii

List of Figures $\quad$ iv

List of Tables $\quad$ V

Abstract 1

Executive Summary - Introduction 2

Goals and Objectives $\quad 3$

Overview 3

Accomplishments $\quad 4$

1. Introduction 6

2. Motivation and Objectives $\quad 7$

3. Technical Approach 8

4. Technology Overview 9

5. Test Facilities 11

5.1 Single Module High Pressure Rig 11

5.2 Saturn Engine 12

5.3 Saturn Engine Facility 14

$\begin{array}{ll}5.4 \text { Engine Controls } & 17\end{array}$

6. Taurus 70 Single Module Test 18

6.1 Unpiloted Module Description 18

6.2 Unpiloted Single Module Light-Off and Testing 20

6.3 Piloted Module Description 25

6.4 Piloted Single Module Test Results 26

7. Saturn Testing 31

7.1 Saturn Combustor Configuration 31

7.2 Single Module Testing at Saturn Conditions 35

7.3 Saturn Engine Demonstration 39

8. Conclusions 45

9. Recommendations 45 


\section{List of Figures}

$\begin{array}{ll}\text { Figure 1 - Schematic of RCL Combustion Process } & 10\end{array}$

Figure 2 - High Pressure Single Injector Test Rig 12

Figure 3 - Simple Cycle Saturn Gas Turbine 13

$\begin{array}{ll}\text { Figure } 4 \text { - Recuperated Saturn Configuration } & 14\end{array}$

$\begin{array}{ll}\text { Figure } 5 \text { - Saturn Test Engine with Side-Mounted Combustor } & 15\end{array}$

Figure 6 - Saturn Engine Side-Mounted Combustor Configuration 15

$\begin{array}{lr}\text { Figure } 7 \text { - Taurus } 70 \text { RCL Module } & 18\end{array}$

$\begin{array}{lr}\text { Figure } 8 \text { - Single RCL Module Test Configuration } & 19\end{array}$

Figure 9 - Module Light-Off: Exit Gas Temperature (Tgas_out_3) and Maximum 21

Catalyst Temperature (Tcat_max) Versus Module Inlet Air Temperature

Figure 10 - Single T70 Module Emissions (Combustor Pressure of 236 psi; Inlet Air 22

Temperature of $810 \mathrm{~F}$ )

Figure 11 - Single T70 Module Combustor Pressure Oscillations 23

Figure 12 - Single T70 Module: Maximum Reactor Surface Temperature 24

Figure 13 - T70 Piloted Module Configuration 27

Figure 14 - T70 Piloted Module: Full Load Conditions 28

Figure 15 - T70 Piloted Module: 50\% Load Conditions $\quad 29$

Figure 16 - T70 Piloted Module: Pressure Oscillations 30

Figure 17 - Saturn RCL Combustor Hardware 32

Figure 18 - Saturn RCL Combustor Assembly 33

Figure 19 - Saturn RCL Combustor Hardware Installed in Combustor Housing (View 34

Forward Looking Aft)

Figure 20 - NOx and CO emissions at Saturn full-load conditions 36

Figure 21 - Single Saturn Module Emissions: Part Load Conditions 37

Figure 22 - Single Saturn Module Emissions: Full Load Conditions with Modified Air 38

Flow Split

Figure 23 - Saturn Engine Parameters During Engine Light-Off 40

Figure 24 - Catalytic Reactor Surface Temperatures During Saturn Engine Light-Off 42

Figure 25 - Saturn Engine Emissions 43 


\section{List of Tables}

1. Turbine Performance Parameters $\quad 17$

2. Taurus 70 Full Load Conditions 19

3. Nominal Saturn Engine Combustor Inlet Conditions 35

4. Saturn Operating Data at Low and High-End of Achievable Operating 44 Range 


\begin{abstract}
A project to demonstrate a near-zero NOx, catalytic combustion technology for natural gas-fired, industrial gas turbines is described. In a cooperative effort between Solar Turbines Incorporated and Precision Combustion Incorporated (PCI), proof-of-concept rig testing of PCI's fuel-rich catalytic combustion technology has been completed successfully. The primary technical goal of the project was to demonstrate NOx and CO emissions below 5pm and 10 ppm, respectively, (corrected to $15 \% \mathrm{O}_{2}$ ) at realistic gas turbine operating conditions.
\end{abstract}

The program consisted of two tasks. In the first task, a single prototype $\mathrm{RCL}^{\mathrm{TM}}$ (Rich Catalytic Lean Burn) module was demonstrated at Taurus 70 (7.5 Mw) operating conditions (1.6 MPa, $16 \mathrm{~atm})$ in a test rig. For a Taurus 70 engine, eight to twelve RCL modules will be required, depending on the final system design. In the second task, four modules of a similar design were adapted to a Saturn engine (1 Mw) test rig (600 kPa, 6 atm) to demonstrate gas turbine light-off and operation with an RCL combustion system.

This project was initially focused on combustion technology for the Mercury 50 engine. However, early in the program, the Taurus 70 replaced the Mercury. This substitution was motivated by the larger commercial market for an ultra-low NOx Taurus 70 in the near-term.

Rig tests using a single prototype RCL module at Taurus 70 conditions achieved NOx emissions as low as $0.75 \mathrm{ppm}$. A combustor turndown of approximately 110C (200F) was achieved with NOx and CO emissions below 3 ppm and 10 ppm, respectively. Catalyst light-off occurred at an inlet temperature of 310C (590F). Once lit the module remained active at inlet air temperatures as low as 204C (400F). Combustor pressure oscillations were acceptably low during module testing. 
Single module rig tests were also conducted with the Taurus 70 module reconfigured with a central pilot fuel injector. Such a pilot will be required in a commercial RCL system for turbine light-off and transient operation. At and near simulated full load engine conditions, the pilot operated at low pilot fueling rates without degrading overall system emissions.

In the second project task, a set of four Taurus 70 modules was tested in an existing Saturn engine rig. The combustion system allowed smooth engine startup and load variation. At steady state conditions (between $82 \%$ and $89.7 \%$ engine speed; $32 \%$ and $61 \%$ load), NOx and CO emissions were below 3ppm and 10ppm, respectively. Rig limitations unrelated to the RCL technology prevented low emissions operation outside of this speed range. Combustor pressure oscillations were low, below $0.25 \%$ (peak-topeak) of the mean combustor pressure.

\section{Executive Summary}

\section{Introduction}

Over the last ten years, industrial gas turbine operators have had to comply with increasingly strict exhaust emissions regulations. These regulations are particularly strict in areas that have severe air quality issues. The exhaust constituents of greatest concern are oxides of nitrogen (NOx) that can act as smog precursors and carbon monoxide $(\mathrm{CO})$.

To meet these regulations, gas turbine manufacturers have introduced lean premixed (LP) combustion systems that have provided impressive NOx emissions reductions. NOx emissions as high as 200 to $300 \mathrm{ppm}$ (corrected to $15 \% \mathrm{O} 2$ ) have been reduced to levels below $25 \mathrm{ppm}$ through the LP combustion of natural gas. In certain areas of the U.S., however, NOx emissions requirements are as low as 2 to $3 \mathrm{ppm}$.

Solar Turbines and Precision Combustion Incorporated (PCI) have completed a project to demonstrate a near-zero NOx, catalytic combustion technology for natural gas-fired, 
industrial gas turbines. Proof-of-concept rig testing of PCI's rich catalytic combustion technology has shown that the technology can meet the most stringent NOx regulations without exhaust gas cleanup. This project was supported by the U.S. Department of Energy and Solar under DOE Contract DE-FC02-00CH11055.

\section{Goals and Objectives}

The ultimate objective of this work is to commercialize a rich catalytic combustion system that will meet the most stringent gas turbine NOx emissions regulations in the U.S. This will allow gas turbine operators to forego the use of expensive exhaust gas cleanup systems. The project described here is a first step in the development of a new generation of near-zero NOx gas turbine combustion systems.

The specific technical goal of the project was to demonstrate the ability of the rich catalytic combustion technology to provide NOx and CO emissions below 5 ppm and 10 ppm (corrected to $15 \%$ O2), respectively. These goals were met in both single catalytic module tests and a Saturn engine technology demonstration. NOx emissions below 1 ppm were achieved during testing.

\section{Overview}

The technology being advanced is a unique, rich catalytic combustion concept developed by PCI. The PCI concept employs two-stage combustion of natural gas. The first stage uses catalytic rich combustion while the second stage is a lean premixed combustion process.

One major task of this program involved the design, fabrication, and rig testing of a rich catalytic combustion module for a Taurus $70(7.5 \mathrm{Mw})$ gas turbine. A complete Taurus 70 combustion system will require up to twelve such modules. The module performance 
was documented at Taurus 70 conditions with excellent emissions results. NOx emissions below 1 ppm were achieved.

In addition to the single module tests, the project involved a brief demonstration of the rich catalytic combustion technology on a Solar Saturn gas turbine (1 Mw) at Solar. The engine demonstration task included the fabrication of four catalytic modules that were integrated into a single, side-mounted combustor for the Saturn.

\section{Accomplishments}

Solar and PCI have successfully demonstrated the technical viability of the rich catalytic combustion concept. The technology has the potential to meet the most stringent gas turbine NOx emissions regulations in the U.S.

This project achieved three significant technical milestones in the development of rich catalytic combustion:

- experimental confirmation of the ultra-low NOx capability of the technology on natural gas in a single combustor module at typical gas turbine conditions (1.7 $\mathrm{MPa}, 17 \mathrm{~atm})$

- demonstration of a prototype Taurus 70 combustor module incorporating a central pilot burner. The pilot provides the wide operational range and transient stability required in an industrial gas turbine without increasing emissions at high engine loads.

- operation of the first gas turbine ever to use a rich catalytic combustion system. The Saturn engine tests demonstrated light-off capability, transient stability, and ultra-low NOx emissions at steady state. 
Further development of the rich catalytic technology is planned beyond this project. This work will involve design evolution of the catalytic module to pre-production status, fabrication of a full set of Taurus 70 modules, integration of the modules into the Taurus 70 combustion system, and rig and engine testing of the hardware. 


\section{Introduction}

Solar Turbines Incorporated is working with the U.S. Department of Energy and subcontractor Precision Combustion Incorporated (PCI) to develop an improved ultralow emissions gas turbine combustion system based on fuel-rich catalytic combustion. Catalytic combustion has the potential to provide a step change reduction in NOx emissions to "near-zero" levels. The use of a rich catalytic reactor within the combustion system allows combustor flame temperature (and thus NOx emissions) to be maintained at lower levels than in today's lean premixed (LP) gas turbine combustors.

The major focus of this project was the rig testing of a unique, rich-catalytic/lean (RCL) combustion technology being advanced by PCI. The test hardware was designed for Solar's 7.5 Mw Taurus 70 (T70) gas turbine. Testing was conducted at T70 operating conditions, thus allowing a realistic assessment of performance and the identification of any technical roadblocks in the commercialization path. The emissions goals of this project were to demonstrate the ability to maintain NOx emissions under 5 ppm and $\mathrm{CO}$ below $10 \mathrm{ppm}$ (both corrected to $15 \% \mathrm{O} 2$ ). More aggressively, the project team targeted sub-3 ppm NOx as a goal. This lower level is representative of the strictest emissions regulations for gas turbines in the U.S.

The majority of testing was conducted in a high-pressure rig at Solar using a single RCL module mounted upstream of a cylindrical combustor liner. A full T70 combustion system may require up to twelve such modules. In addition, the project involved a short demonstration of the RCL technology on a Solar Saturn gas turbine (1 Mw) at Solar. The Saturn demonstration included the design, fabrication, installation and short-term testing of a side-mounted, catalytic combustor for the Saturn. The Saturn combustion system utilized four modules of the T70 design that were reoptimized for Saturn operating conditions. 
The Saturn testing was intended only as a technology demonstration. It did not involve the long-term testing needed to demonstrate the durability of the RCL module. The Saturn testing was conducted to demonstrate, for the first time, the functionality of and emissions from a prototype RCL system on a gas turbine. The project was not focused on developing the Saturn RCL system as a commercial offering.

\section{Motivation and Objectives}

A major challenge for gas turbine manufacturers is the further reduction of already low NOx emissions from today's LP gas turbines. It is anticipated that current NOx emissions guarantees (near $25 \mathrm{ppm}$ ) will have to be reduced to $9 \mathrm{ppm}$ in the future. Areas with particularly severe air quality problems have already set NOx emissions limits at 2.5 ppm.

These stricter NOx emissions limits are forcing gas turbine operators to either install expensive exhaust gas cleanup systems downstream of their turbines or forego using gas turbines and purchase power from the grid. The result has been and will continue to be a brake on the use of gas turbines for cogeneration and distributed generation. This is placing further demands on the already tight electric utility infrastructure in the U.S.

Ironically, the gas turbine is now recognized as an ideal prime mover for power generation. The gas turbine is playing a major role in the U.S. in terms of increased energy efficiency, "greenhouse" gas reduction, reduced electricity costs, and a more diverse and reliable electric power infrastructure. These benefits are associated with use of gas turbines in distributed power generation and cogeneration service. In the future, gas turbines are expected to contribute further through their application in advanced combined cycles and gas turbine/fuel cell systems.

The objective of this effort is to advance to engine readiness, a rich catalytic combustion 
system that will meet the most stringent gas turbine NOx emissions regulations in the U.S. The focus is on a unique, two-stage catalytic combustion technology developed by PCI. The RCL concept employs a catalytically-assisted rich combustion process followed by lean premixed combustion. The ultimate motivation for developing the RCL system is to commercialize an ultra-low NOx emissions technology that is less expensive than today's exhaust gas cleanup systems.

\section{Technical Approach}

The technical approach adopted for this program followed Solar's established methodology for the development of low emissions combustion technologies. Following the identification of a new "concept" (or component) with reduced emissions potential, emissions improvements are documented in rig tests at simulated gas turbine conditions. Test hardware at this time is at the early prototype stage. Testing typically involves a single, full scale fuel injector or module in a can combustor configuration. The single module tests precede full system tests that typically require the fabrication of multiple injectors or modules. The single module rig tests are conducted to document and optimize emissions performance within the operating constraints of the component (material temperatures, pressure drop, etc). These tests support the evolution of the design to a pre-production level.

Subsequently, a full set of pre-production hardware is fabricated as the testing advances to the full system level (multiple injectors/modules). System testing involves rig tests at atmospheric pressure and then high pressure (if feasible). The full system rig testing allows full-load and part-load performance verification as well as measurement of the combustor pattern factor, radial exit temperature profile, material temperatures, and system light-off characteristics. Ultimately, the test hardware is advanced to an in-house engine test and then one or more long duration field evaluations. The field evaluations precede the release of the hardware for production. 
The rich catalytic combustion work reported here reflects the first stages of the commercialization scenario described above. A single catalytic module was designed and fabricated for T70 operating conditions. This module was used in a series of high pressure rig tests in conjunction with a $20 \mathrm{~cm}$ (8 inch) diameter can combustor. The single module tests were run to demonstrate the ultra-low NOx capability of the module and to optimize its performance.

Following the single module tests, a multi-module test was conducted in an existing small gas turbine test facility (1.0 Mw Saturn) at Solar. The Saturn testing was conducted using a set of four catalytic modules clustered so as to fire into a single $39 \mathrm{~cm}$ diameter $(15.25$ inch) can combustor. The engine testing allowed an early evaluation of multi-module light-off, module performance during engine start and load transients, and emissions (although at lower pressures and combustor inlet temperatures than in a T70).

As a final project task, a single T70 module was modified to include a central pilot flame to enhance the operational range of the module. The pilot is of a "partially premixed" design and is non-catalytic. In a production turbine the pilot is needed to provide combustor stability during light-off and rapid load changes. Testing of the piloted module established that the presence of the pilot did not degrade the low emissions capabilities of the catalytic module.

Further development of the rich catalytic technology is planned beyond the present project. Design evolution of the catalytic module to pre-production status, fabrication of a full set of T70 modules, and full system rig and engine tests are the next technical steps to commercialization.

\section{Technology Overview}


The RCL concept was developed by PCI to resolve technical issues associated with lean catalytic combustion for gas turbines. The most critical issue was avoiding excessive catalyst or substrate temperatures by limiting the amount of fuel burned within the catalytic reactor. At the same time, however, sufficient gas temperature rise must occur in the reactor to support lean gas-phase combustion in a second combustor stage downstream of the reactor. This second, fuel-lean combustion process must take place at the low flame temperatures required to limit NOx emissions to ultra-low levels.

The RCL combustion concept is illustrated Fig. 1. The system includes a fuel/air premixer, a rich catalytic reactor, a post-reactor mixing section and a lean combustion zone. The first three elements together comprise the RCL "module".

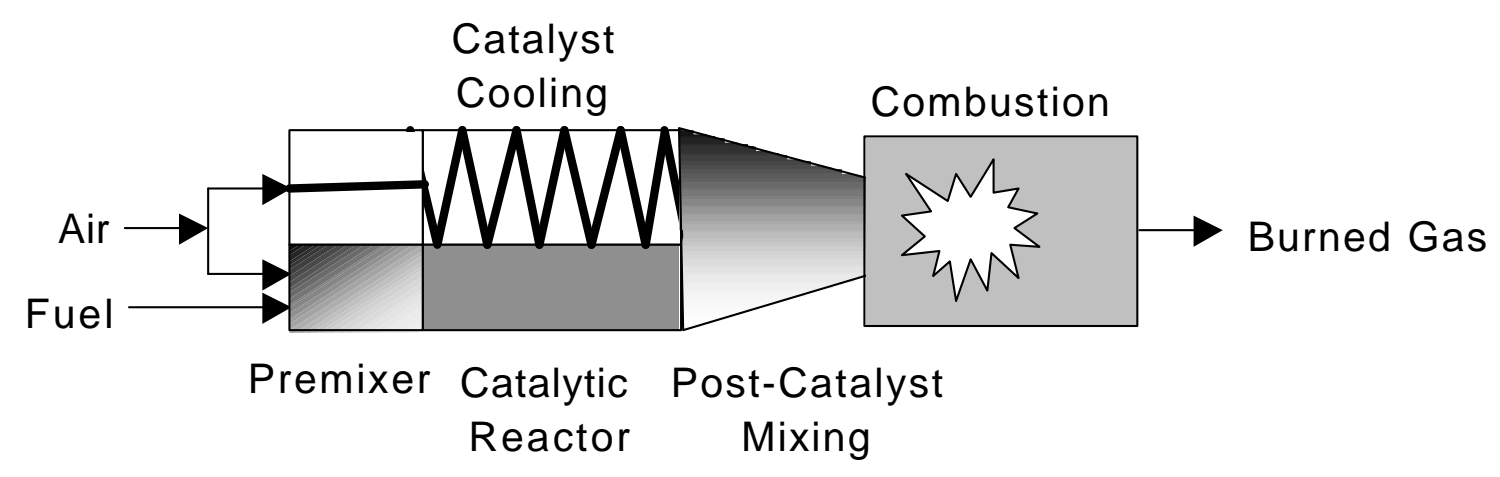

Figure 1 - Schematic of RCL Combustion Process

As shown in Fig. 1, there are two distinct air streams that enter the module. One air stream enters the fuel/air premixer, mixes with the fuel and then flows into the catalytic reactor. The mixture entering the reactor is fuel rich. A second air stream is used to cool the reactor.

Within the reactor, there is insufficient oxygen to fully burn all of the fuel, although a significant gas temperature rise does occur. To complete the combustion process, additional air is injected downstream of the reactor. The air stream used to cool the reactor also serves as this additional air. 
The hot, partially reacted fuel/air stream exiting the reactor and the reactor cooling air (now also hot) are mixed rapidly in the post-mix zone immediately downstream of the reactor. This mixture (now fuel lean) then flows to the lean combustor where the unreacted fuel is consumed. The high temperature of the mixture entering the lean combustor allows this second combustion process to occur at unusually low flame temperatures where NOx formation is negligible.

In a gas turbine RCL system, additional air (dilution air) is injected at the exit of the combustor to reduce the gas temperature to the desired turbine inlet temperature. The specific distribution of air within the combustion system is dependent upon the gas turbine operating conditions as well as the conversion efficiency of the catalytic reactor.

Among the benefits provided by RCL combustion are:

- wide choice of catalyst type

- potential for improved catalyst durability as the catalyst is in a non-oxidizing environment

- and low catalyst light-off temperature. The low catalyst light-off temperature means that no preburner is required in a modern, high pressure ratio turbine.

\section{Test Facilities}

\subsection{Single Module High Pressure Rig}

Testing of single RCL modules was conducted in the high pressure rig shown in Fig 2. The test facility can provide $3.6 \mathrm{~kg} / \mathrm{s}$ ( $8 \mathrm{pps}$ ) of air at pressures up to $2.1 \mathrm{MPa}$ (300 psig). An indirect air heater can boost inlet air temperatures to $650 \mathrm{C}(1200 \mathrm{~F})$. 


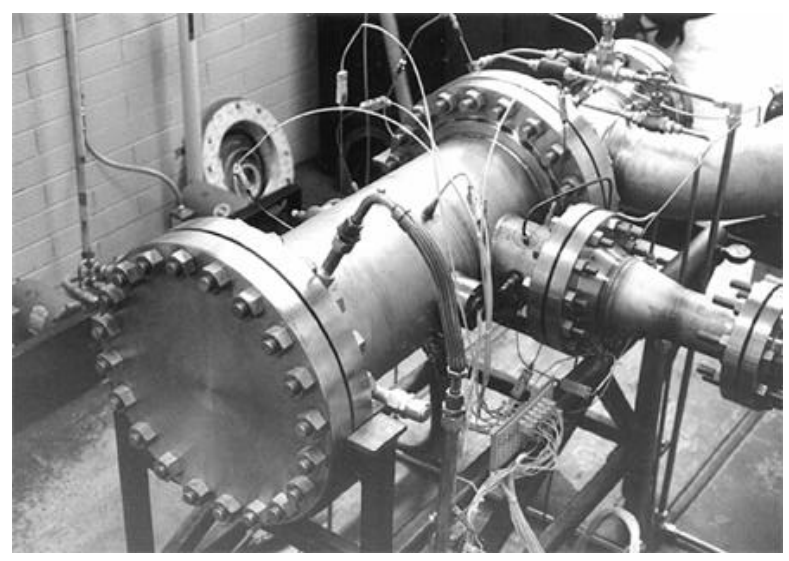

Figure 2 - High Pressure Single Injector Test Rig

Air entering the rig is split into two streams. One stream (primary zone air) flows to the RCL module while the other stream (dilution air) cools the lean combustor and then mixes with the combustion products exiting the combustor primary zone. Downstream of the combustor, the hot gases are quenched by a water spray and then exhausted to the atmosphere through a back-pressure valve. The rig is instrumented to monitor fuel and air flows, system pressures and temperatures, and emissions (NOx, $\mathrm{CO}, \mathrm{CO} 2, \mathrm{O} 2, \mathrm{UHC}$ ). A production torch igniter or a spark igniter can be used to initiate combustion in the test rig.

\subsection{Saturn Engine}

The Saturn was the first axial flow gas turbine manufactured by Solar. It was introduced in 1960 as an $1100 \mathrm{hp}$ machine and over the years has been up-rated to $1600 \mathrm{hp}$. Over 4800 Saturn turbines have been sold.

A cross-section of the production Saturn is shown in Fig 3. It is comprised of an eightstage axial compressor, an annular combustor with nine fuel injectors, and a three stage axial turbine. One-shaft and two-shaft configurations are produced for power generation and mechanical drive applications, respectively. No LP combustion system has been commercialized for the Saturn. On natural gas, Saturn NOx emissions are in the 50 to 60 ppm range. 


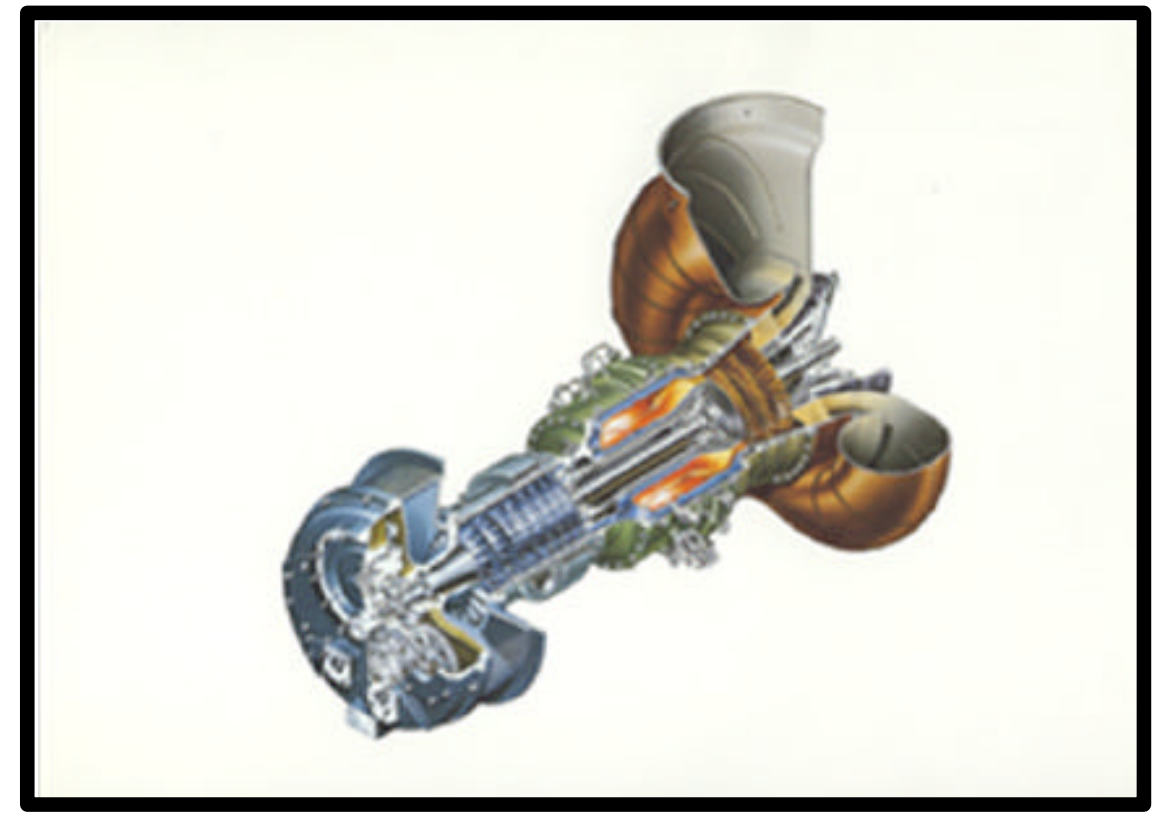

Figure 3 - Simple Cycle Saturn Gas Turbine

A recuperated version of the two-shaft T1200 Saturn engine (but with no recuperator) was available for module testing in this program. Figure 4 illustrates its general configuration. Of particular value to the program was the engine's use of a side-mounted combustor that could be readily adapted to the RCL configuration. 


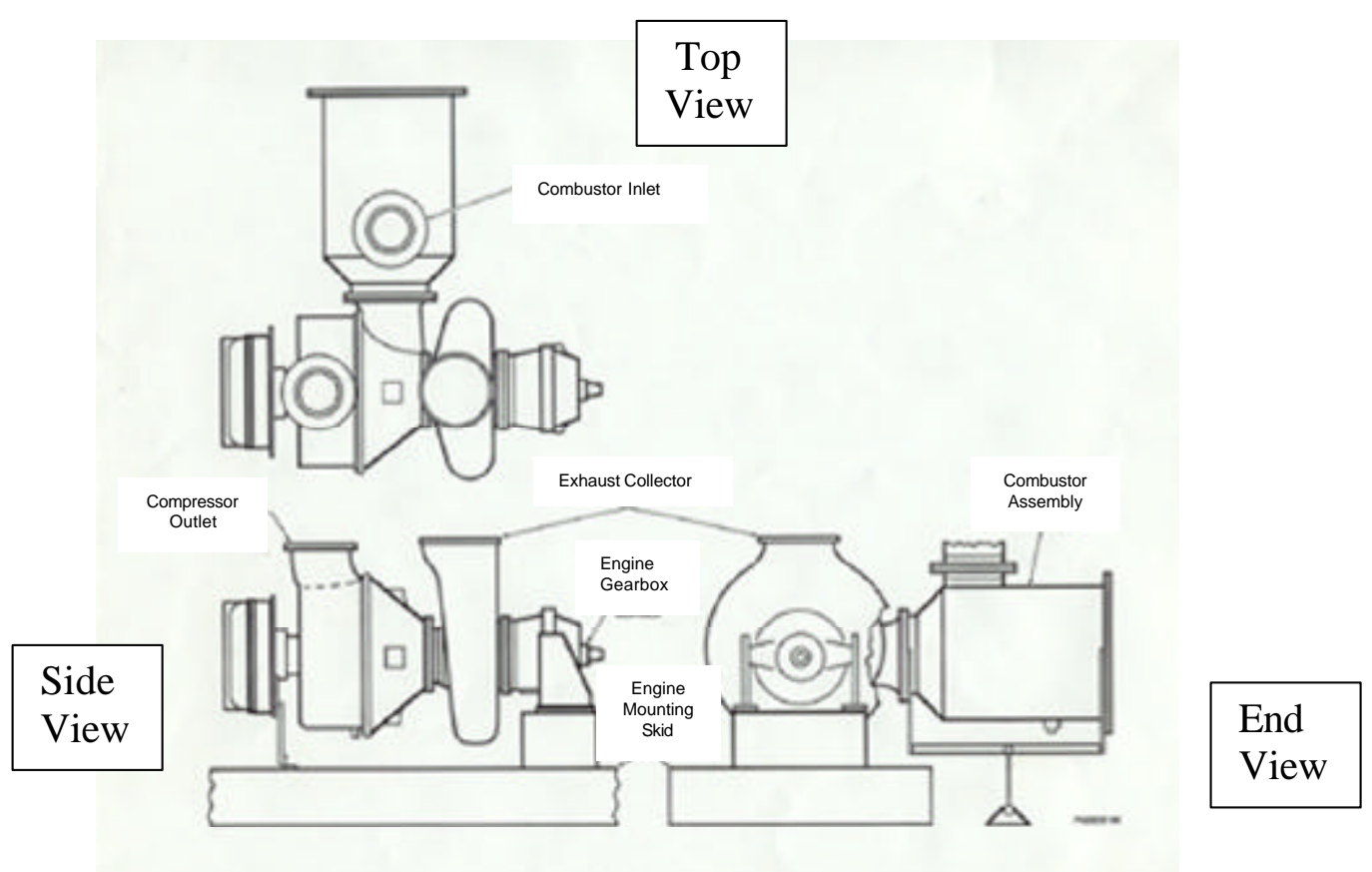

Figure 4 - Recuperated Saturn Configuration

Although the Saturn operates at lower pressures and temperatures than the T70, the Saturn facility, already in existence, provided an opportunity for an early, cost-effective evaluation of the transient performance of the RCL system.

\subsection{Saturn Engine Facility}

The Saturn test facility employs a unique (non-production) configuration as shown in Figs. 5 and 6 . From the engine inlet to the compressor diffuser, the internal engine hardware is identical to a production T1200 Saturn two-shaft engine. However, the test engine used a recuperative Saturn compressor housing. This housing ducts the compressor airflow away from the engine to a piping run that feeds air to the off-base combustor. The piping run includes a pair of down-comer air ducts. One air duct feeds the RCL modules; the second delivers dilution air. Butterfly valves mounted in two air ducts allow the flow distribution to be controlled between the two zones. This provides considerably more operating flexibility than a commercial package. 


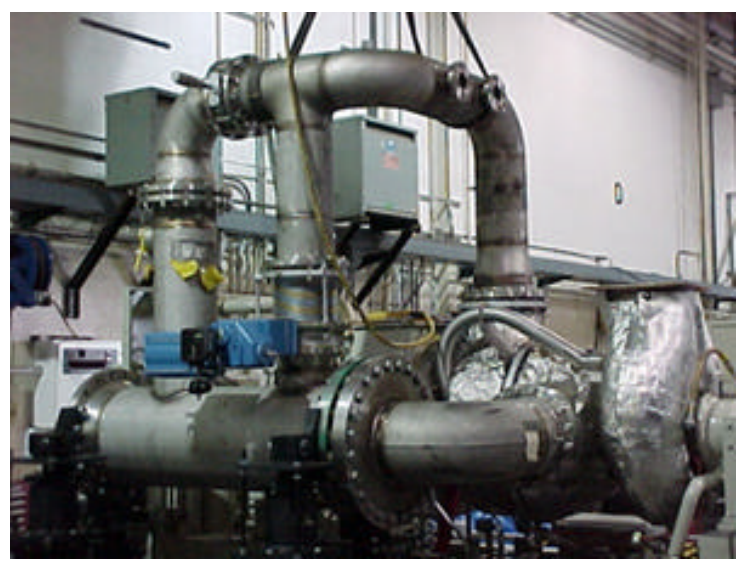

Figure 5 - Saturn Test Engine with Side-Mounted Combustor

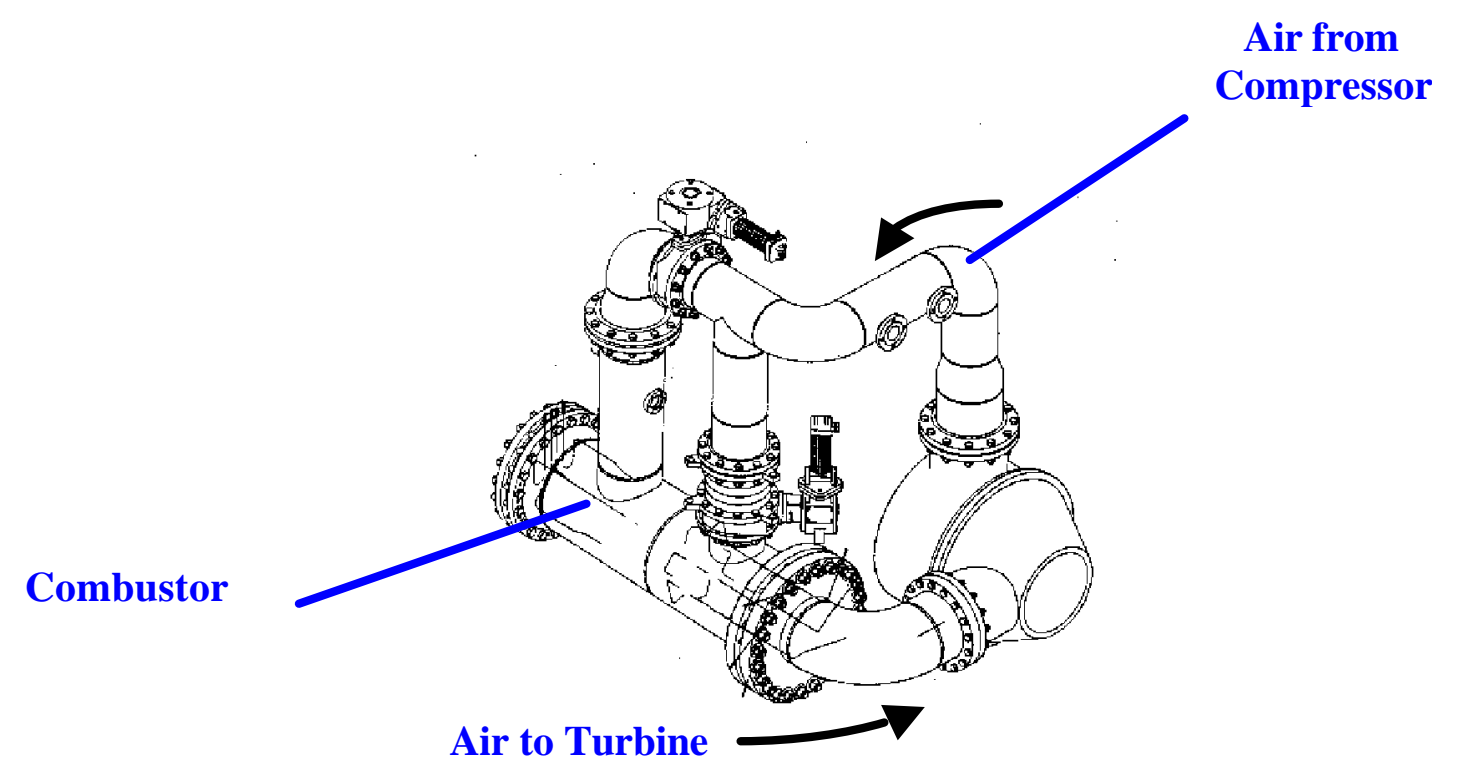

Figure 6 - Saturn Engine Side-Mounted Combustor Configuration (Engine not shown)

For the Saturn tests, it was necessary to mount a preburner in the primary air duct upstream of the RCL modules to initiate catalyst light-off. During light-off the preburner raised the reactor inlet air temperature to $315 \mathrm{C}(600 \mathrm{~F})$. The preburner was extinguished once reactor light-off was achieved. 
From the preburner, the primary air flows to the catalytic module. Partial combustion occurs within the module with the hot exhaust then entering the lean combustor. In the lean combustor, non-reacted fuel is burned. Air from the second air duct enters the combustor housing at its downstream end. This dilution air is used to cool the combustor and then injected into the main gas stream through two rows of dilution holes.

The combustor exhaust flow is then ducted back to the engine. A turbine housing/scroll assembly from a recuperative Saturn is used to distribute the flow around the annular inlet of the turbine. Downstream from the turbine inlet plane, the test engine uses standard Saturn hardware. The facility uses a water dynamometer to load the engine.

For the Saturn testing, a multi-port gas-sampling probe was mounted in the engine exhaust stack. Gas samples were transported from the probe to the emissions analyzers through heated hoses. The emissions instrumentation included $\mathrm{CO}, \mathrm{CO} 2$, UHC, NOx and $\mathrm{O} 2$ analyzers.

The test facility was instrumented to allow documentation of engine and combustor performance. Table 1 provides a list of the operating parameters that were either measured directly or calculated from other measurements. 
Table 1. Turbine Performance Parameters

\begin{tabular}{|l|l|}
\hline Parameter & Location \\
\hline Emissions & Exhaust stack (NOx, $\left.\mathrm{CO}, \mathrm{CO}_{2}, \mathrm{O}_{2}, \mathrm{UHC}\right)$ \\
\hline Speed & Gas producer, power turbine \\
\hline Temperature & $\begin{array}{l}\text { Inlet air, compressor discharge, pre-burner exit, pre-catalyst } \\
\text { mixing zone, catalyst surface, catalyst exit, combustor wall, } \\
\text { turbine scroll inlet, power turbine inlet, exhaust, fuel }\end{array}$ \\
\hline Pressure & $\begin{array}{l}\text { Compressor discharge, fuel, preburner fuel, fuel module A and } \\
\text { fuel module B }\end{array}$ \\
\hline Pressure Drop & $\begin{array}{l}\text { Exhaust, preburner fuel, catalyst fuel, pre-burner air valve, } \\
\text { dilution air valve }\end{array}$ \\
\hline Fuel Flow & Pre-burner, catalyst module set A and B \\
\hline Air Flow & $\begin{array}{l}\text { Calculated from venturi at the compressor intake, air valve } \\
\text { setting, and pre-burner temperature rise }\end{array}$ \\
\hline
\end{tabular}

\subsection{Engine Controls}

The Saturn engine control system used an Allen-Bradley microprocessor to run unique control logic. The combustor fuel system was divided into three sub-circuits:

- preburner

- RCL modules 1 and 2

- RCL modules 3 and 4

Each sub-circuit contained its own fuel control valve and shutoff valve. Control software included standard engine logic that modulated total fuel flow to the engine in response to 
a signal based on engine load. The control logic was augmented by three unique closed loops. Each of the closed loops was allocated to one of the three fuel sub-circuits and controlled the fuel flow through its sub-circuit.

\section{Taurus 70 Single Module Tests}

\subsection{Unpiloted Module Description}

The T70 RCL module (Fig. 7) was sized to replace one of the twelve lean premixed injectors used in a production T70. The module was $7.6 \mathrm{~cm}(3.0 \mathrm{inch})$ in diameter and approximately $38 \mathrm{~cm}$ (15 inches) long. T70 operating conditions are presented in Table 2.

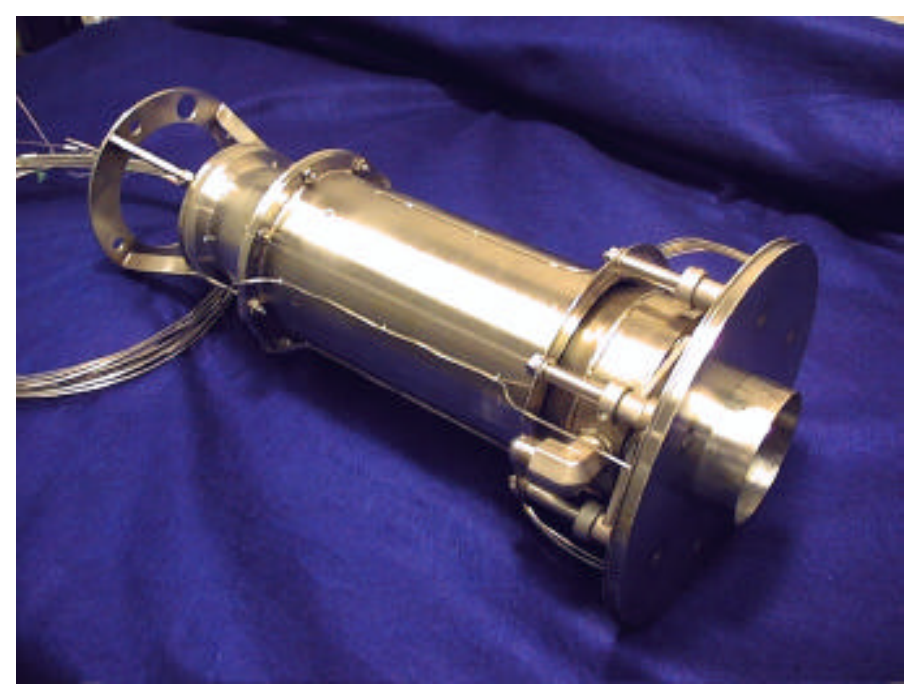

Figure 7 - Taurus 70 RCL Module 


\section{Table 2. Taurus 70 Full Load Combustor Operating Conditions}

\begin{tabular}{|cc|}
\hline Air flow & $48.85 \mathrm{lb} / \mathrm{sec}$ \\
Inlet Temperature & $800 \mathrm{~F}$ \\
Inlet Pressure & $232.5 \mathrm{psia}$ \\
Fuel Flow & $1.02 \mathrm{lb} / \mathrm{sec}$ \\
Fuel Temp & $250 \mathrm{~F}$ \\
\hline
\end{tabular}

A cross-section of the module/lean combustor assembly is shown in Fig. 8. Called out in Fig. 8 are the module components: the annular fuel/air premixer, the catalytic reactor, and the post-mix duct/stabilizer assembly. The module mates with the upstream end of the combustor liner. For the single module tests reported here, the combustor liner was a back-side cooled cylinder with a diameter of $20 \mathrm{~cm}$ (8.0 inches). Dilution air was injected through four $1.3-\mathrm{cm}(0.5$-inch) diameter holes at the liner's downstream end.

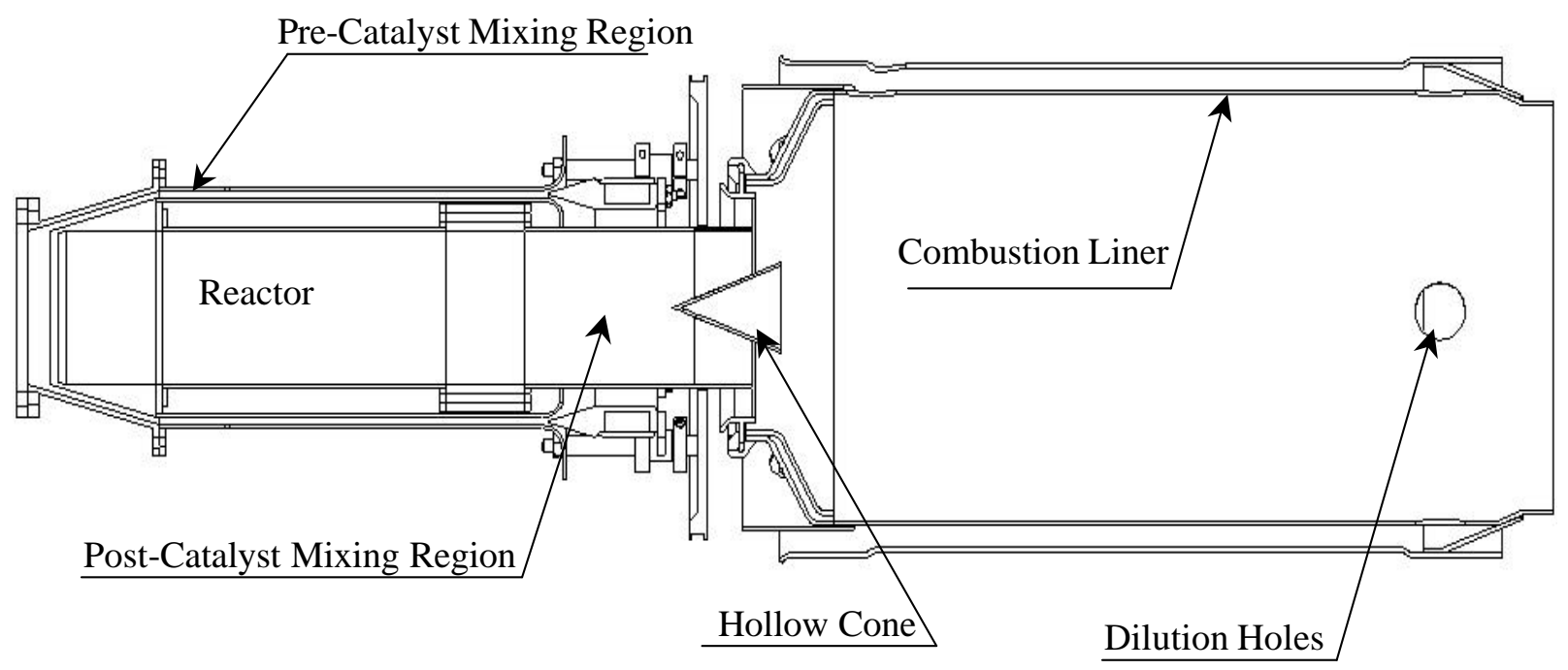

Figure 8 - Single RCL Module Test Configuration 
Along with standard facility instrumentation, the module was instrumented to measure reactor surface temperatures as well as gas composition and temperature in the premixing and the post-mixing zones.

The fuel/air premixer is an annular, reverse flow device and is located outboard of the catalytic reactor. The premixer delivers a premixed fuel-rich mixture to the reactor. Approximately $15 \%$ of the module air is mixed with the fuel in the premixer. The remaining module air is used for the reactor cooling. Reactor cooling air enters the module from the upstream end (left-hand side in Fig. 8).

The heart of the catalytic module is the catalytic reactor. The reactor is essentially a tubular, co-flow heat exchanger. The outside surfaces of the tubes in the tube bundle are coated with a washcoat and the catalyst. Oxidation occurs as the fuel-rich fuel/air mixture flows over the outside of the tubes. Cooling air passes through the inside of the tubes and acts to maintain tube and catalyst temperatures at acceptable levels. Downstream of the reactor, the reactor exhaust and the cooling air combine in the postreactor mixing zone.

As shown in Fig. 8, the post-mix duct is inserted into the upstream end of the combustor liner. A flame-holding cone (20 degree half-angle) within the post-mix duct serves as a flame stabilizer for the final, lean combustion process in the combustor liner. Late in the program, the stabilizer cone was replaced with a pilot fuel injector. The first module tested, however, included no provision for fuel staging (no pilot injector).

\subsection{Unpiloted Single Module Light-Off and Testing}

To achieve reactor light-off, the desired air and natural gas flow rates were established. Then the inlet air temperature was increased gradually from approximately 320 to $420 \mathrm{C}$ (610 to $790 \mathrm{~F})$. At a temperature just over $320 \mathrm{C}(610 \mathrm{~F})$, the reactor ignited, as indicated 
by reactor surface temperatures above the inlet temperature. This light-off event is shown in Fig. 9, where reactor surface temperature is plotted versus rig inlet air temperature.

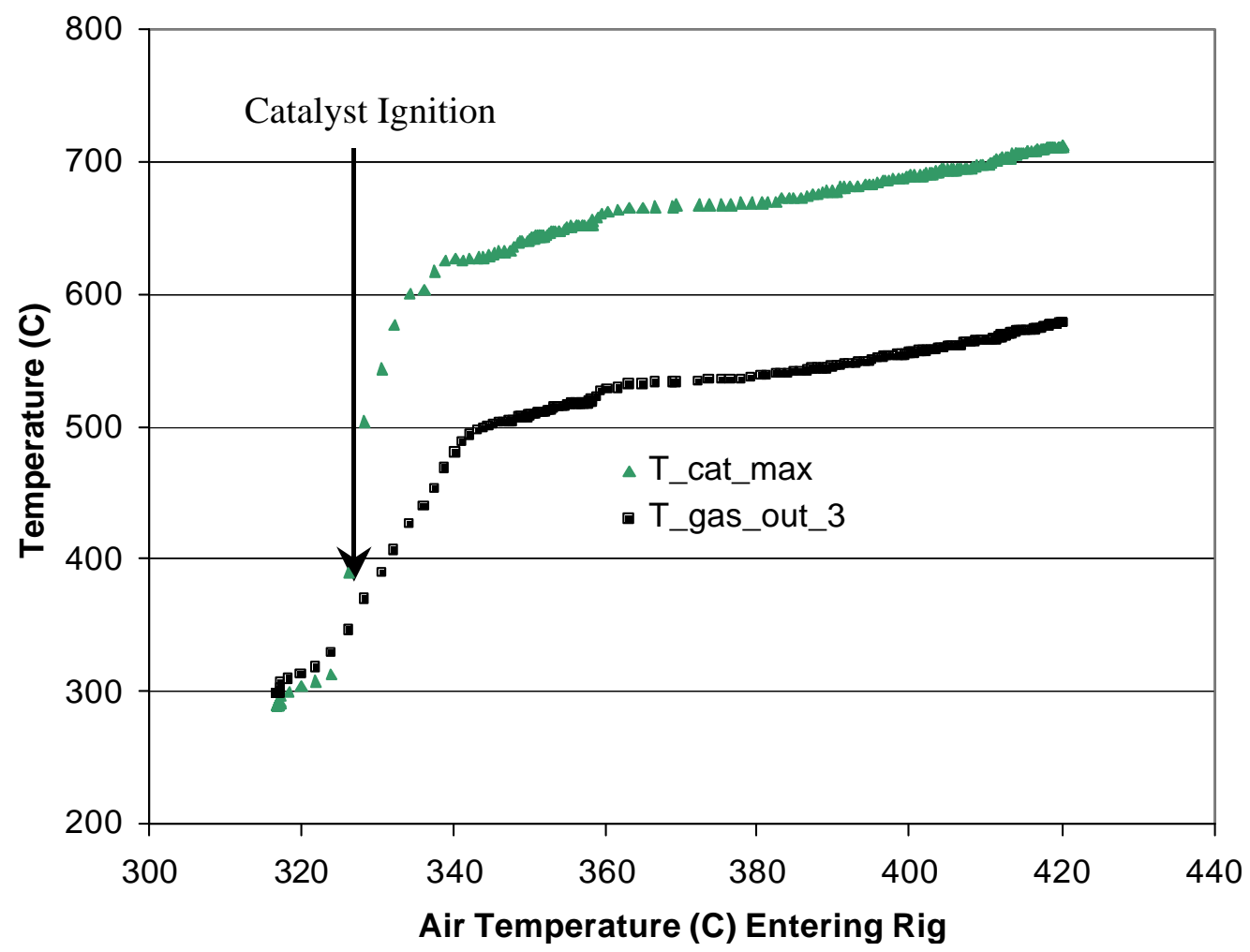

\section{Figure 9 - Module Light-Off: Exit Gas Temperature (Tgas_out_3) and Maximum Catalyst Temperature (Tcat_max) Versus Module Inlet Air Temperature}

After reactor light-off, rig inlet temperature was increased to the T70 full load condition of $430 \mathrm{C}(810 \mathrm{~F})$. At steady airflow conditions, fuel flow was increased to a value above the full load fuel flow condition, and steady-state data were obtained. Fuel flow was then decreased incrementally, and steady-state data were obtained at each increment.

Eventually the combustion process approached lean blowout as indicated by rapidly increasing and/or fluctuating $\mathrm{CO}$ emissions.

NOx and CO emissions from steady state module testing at T70 full load conditions are shown in Fig. 10 as functions of adiabatic flame temperature (Tad) in the combustor 
primary zone (before dilution air injection). Tad was calculated from gas composition (fuel/air ratio) measurements using a gas chromatograph (GC). All emissions data are corrected to $15 \% \mathrm{O} 2$.

As shown in Fig. 10, the RCL combustion system was capable of providing ultra-low emissions over a relatively wide range of flame temperature ( 110C, 200F). Over this range NOx remained below 3 ppm (and as low as $0.7 \mathrm{ppm}$ ) with $\mathrm{CO}$ below $10 \mathrm{ppm}$. UHC remained less than $2 \mathrm{ppm}$.

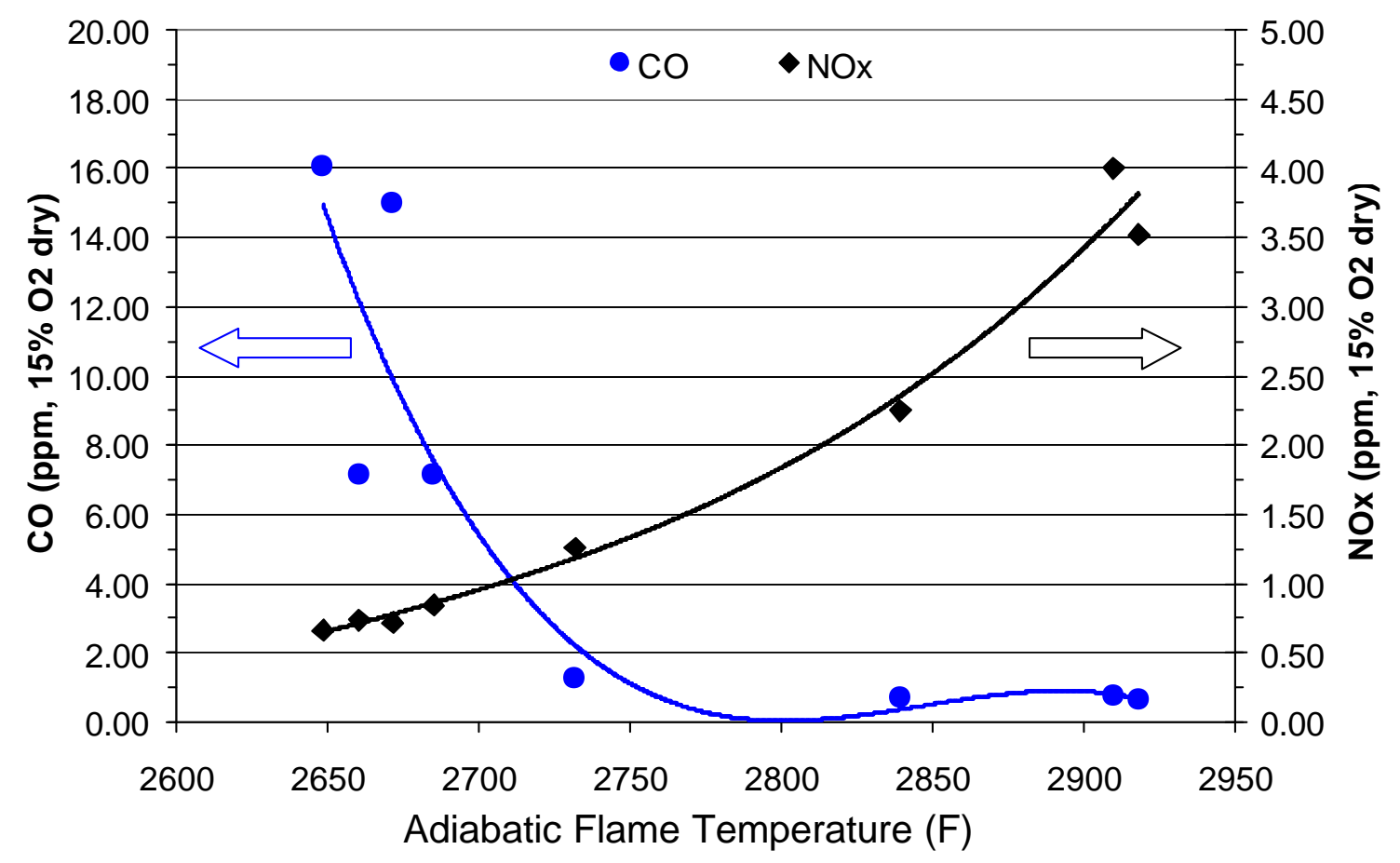

\section{Figure 10 - Single T70 Module Emissions (Combustor Pressure of 236 psi; Inlet Air Temperature of 810F)}

As an accuracy check, Tad was also calculated independently using gas samples taken from the downstream end of the combustor. Gas samples extracted from this location indicated that Tad was about $130 \mathrm{C}(230 \mathrm{~F})$ lower. The most probable cause of this discrepancy was air leakage into the primary zone at the interface of the module and the combustor liner. The uncertainty in Tad does not affect the accuracy of the emissions data. It does, however, cause uncertainty in defining the optimum Tad for minimum emissions. Further tests can easily resolve this uncertainty. 
The combustion system pressure drop at T70 full load conditions was less than $5 \%$ of the combustor inlet pressure. Combustor pressure oscillations were low, less than $2.4 \mathrm{kPa}$ (0.35 psi) peak-to-peak (less than $0.15 \%$ peak-to-peak of mean combustor pressure). Pressure oscillations are expected to be low with RCL combustion since energy release (the driving force for oscillations) is distributed between two combustion zones, the reactor and the liner. In conventional lean combustion systems, the heat release is concentrated in a single zone, increasing the potential for high magnitude pressure fluctuations. Peak oscillation amplitudes occurred over a frequency range of 295 to 320 Hz; peak amplitudes are shown in Fig. 11.

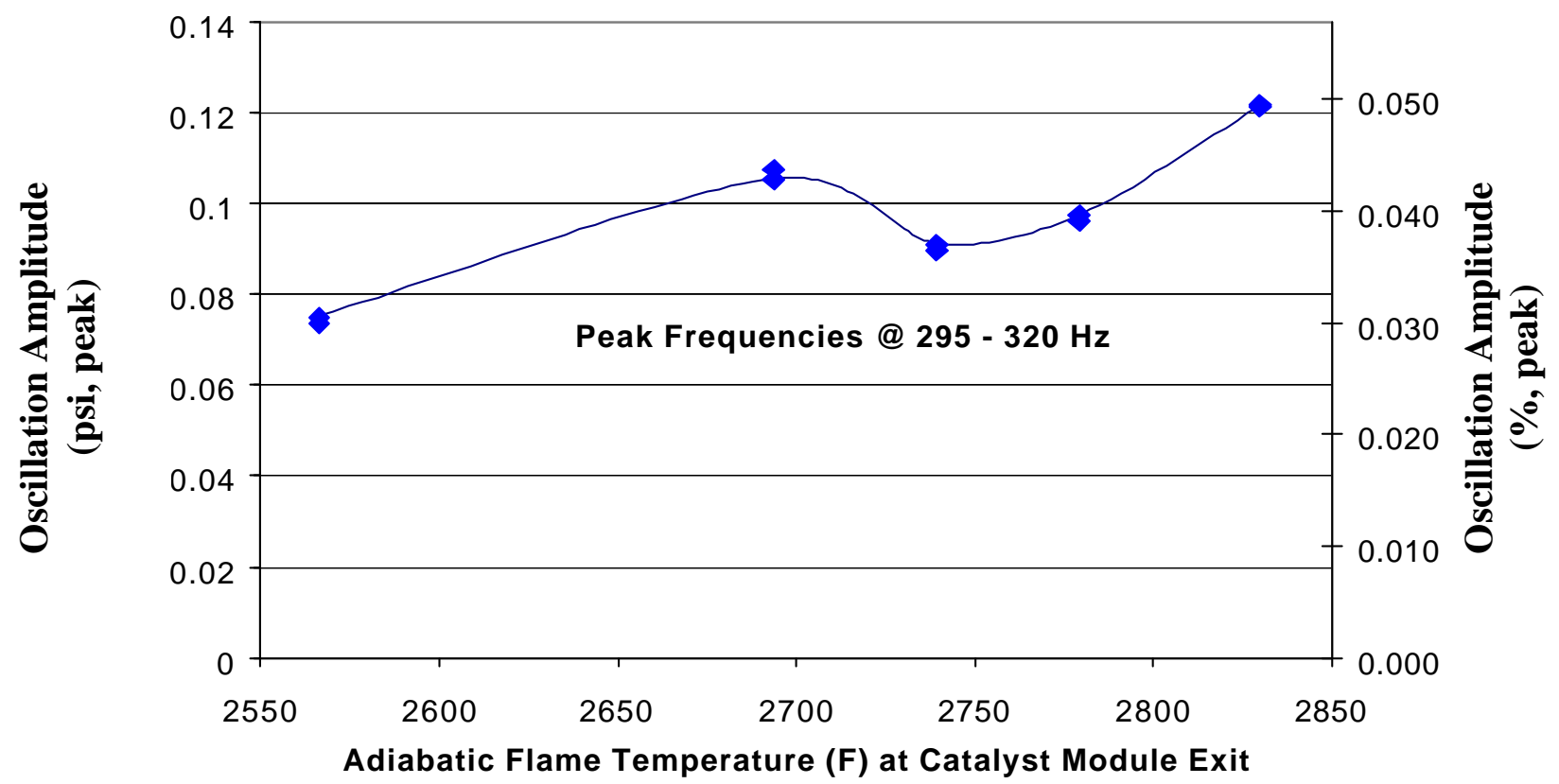

Figure 11 - Single T70 Module Combustor Pressure Oscillations

Figure 12 shows maximum steady-state reactor surface temperature data plotted against Tad. Surface temperatures remained acceptably low over the range of operating conditions tested. Reactor surface temperature decreased slightly as Tad (and fuel flow) 
was increased. A decrease is expected as increased fuel flow moves the fuel/air ratio in the reactor to a richer stoichiometry (to lower temperature). At the same time, Tad in the combustor is increasing as the lean combustion process is moving closer to stoichiometric conditions.

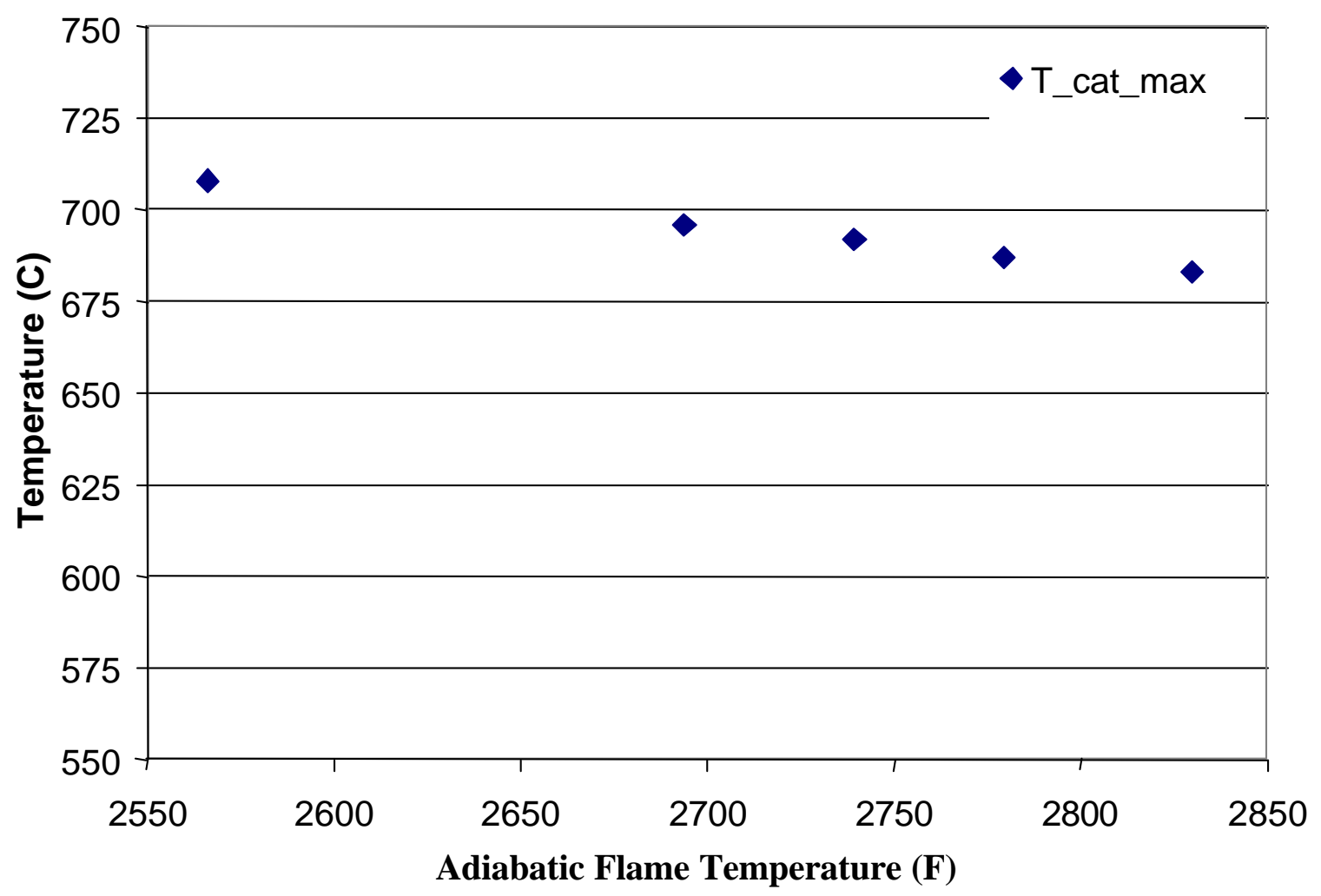

\section{Figure 12 - Single T70 Module: Maximum Reactor Surface Temperature}

The relative insensitivity of reactor surface temperature to fuel/air ratio is advantageous. It allows combustor operation over a wide range of flame temperatures (including flame temperatures well outside of the low emissions operating range) without the risk of reactor dama ge. This operating flexibility will also enhance the ability of the RCL system to operate safely during rapid changes in engine load. 
Reactor temperatures are insensitive to fuel/air ratio because the fuel consumption rate (heat release) at the catalyst surface is controlled by the diffusion of oxygen to the surface, not the local fuel concentration. Thus, fuel flow rate has little effect on reaction rate. For the results presented here, the catalyst was primarily selective to full oxidation products $(\mathrm{CO} 2$ and $\mathrm{H} 2 \mathrm{O})$ over the range of fuel/air ratios tested.

The high pressure module tests were successful in demonstrating the ultra-low emissions capabilities of the RCL combustion system. Fuel-rich catalytic reactions can stabilize fuel-lean premixed combustion to provide stable, quiet combustor operation with ultralow NOx and CO emissions.

\subsection{Piloted Module Description}

A key requirement of any gas turbine combustion system is to sustain combustion during transient operation. Transient conditions include:

. engine light-off and acceleration to idle

. application of load to the engine

. off-loading of the engine

A rapid, full off-load transient (drop in load from 100\% to idle) is typically the most severe event experienced by a GT combustion system (and its associated control system).

The use of small "pilot" fuel injectors to enhance combustor stability has been common in the gas turbine industry since the introduction of LP combustion technology. Lean combustion systems, although capable of providing low emissions, are not sufficiently stable to meet the transient operating characteristics of many gas turbines. This is particularly true for turbines in power generation applications where load can be shed nearly instantaneously.

Pilot injectors operate in parallel with the primary injectors and are designed to have better stability than the main burner. They rely on either a diffusion or partially premixed 
flame. Although not premixed, the pilot injector contributes little to total NOx emissions as only a few percent of the total fuel flow is burned using the pilot (when in the low emissions operating mode). In addition to stabilizing the combustion process during transients, pilot flames are frequently used to reduce the intensity of combustor oscillations that occur in many LP combustion systems.

The pilot operates in two modes. During engine light-off and at low load (outside the low emissions operating range) the pilot provides a substantial portion of the fuel flow. Under these conditions, engine emissions may well be above regulated limits, but operation in these regimes is short-lived. In the low emissions mode, pilot fuel flow is cut back to the minimum required for acceptable stability and low combustor pressure oscillations.

Following the successful demonstration of the RCL modules in the Saturn test facility, a task was undertaken to address the integration of a pilot injector in the baseline RCL module design. The primary goal was to demonstrate that a pilot could be integrated into the RCL module and operate (at a low fueling rate) without substantially increasing total NOx emissions. For a sub-3 ppm NOx combustion system, pilot design will be critical in allowing the gas turbine to operate over a wide load range (at least 50 to 100\% load) with low emissions. This task was envisioned as a proof-of-concept test. The goal was not to develop a production pilot design.

The pilot concept adopted for the T70 module is depicted in Fig. 13. The pilot was located along the central axis of the module. This necessitated the removal of reactor tubes from this central region. To maintain the same reactor capacity, those tubes removed near the axis would have to be relocated around the periphery of the module. For the sake of this test, tube relocation was not undertaken. Instead seventeen of the 121 tubes of the module were simply removed. Although this reduced the module capacity by $15 \%$, the goal of the test could still be achieved with the modified module. This avoided the cost and time necessary to design and fabricate an entirely new module for the purpose of demonstrating piloted (two-stage) operation. 


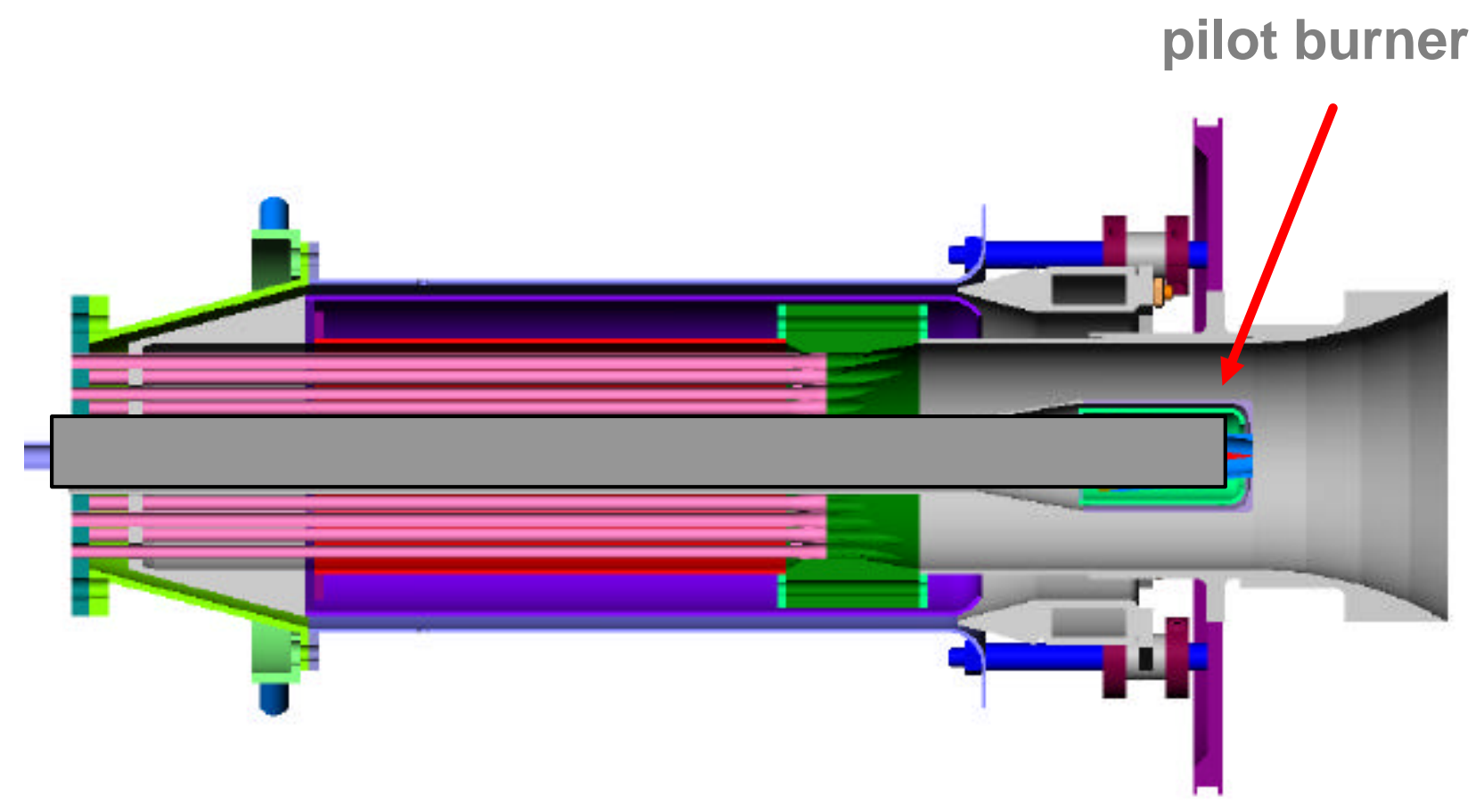

Figure 13 - T70 Piloted Module Configuration

\subsection{Piloted Single Module Test Results}

The piloted T70 module was evaluated in the high pressure rig in the same manner as the unpiloted module. An additional experimental parameter in these tests was the pilot fuel flow rate. Pilot fuel flow rate was quantified as a percentage of the total combustor fuel flow.

Figure 14 presents the high pressure, piloted module emissions data at simulated full load conditions. The results are generally similar to the unpiloted module emissions data. 


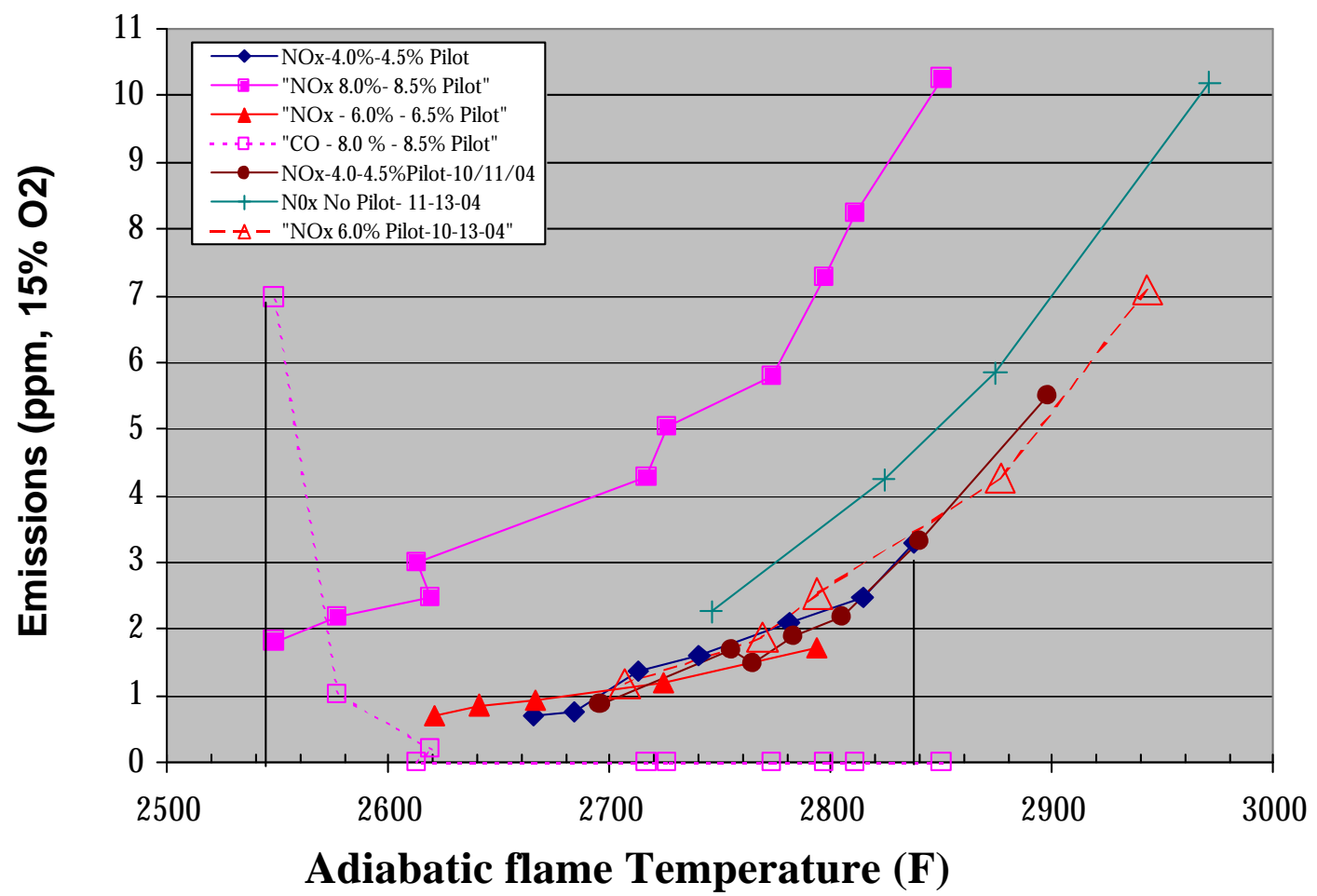

Figure 14 - T70 Piloted Module: Full Load Conditions

The best results were achieved with pilot fueling on the order of 4 to $6 \%$. Operation below 3 ppm NOx with virtually no $\mathrm{CO}$ was demonstrated at these pilot flows over a range of Tad of approximately $250 \mathrm{C}(482 \mathrm{~F}$ ). As pilot fueling was increased to $8 \%$, there was a significant degradation in NOx emissions with NOx rising above $3 \mathrm{ppm}$.

Figure 14 also illustrates that the piloted module shows a degradation in performance (relative to the unpiloted module, see Fig. 10) if the pilot is not fueled. In this instance, the pilot air flow degrades flame stability at the leanest overall conditions. The module is unable to provide a wide range of operation below $3 \mathrm{ppm}$ as was seen previously. However, since the pilot will be fueled continually in a production combustion system, this loss of stability is not a performance factor. 
Figure 15 shows additional data for the piloted module at simulated 50\% load. Although fewer data were collected, the results support the conclusion that pilot fueling at or below $6 \%$ should allow the T70 module to maintain NOx below $3 \mathrm{ppm}$.

\section{Halfload Emissions D ata}

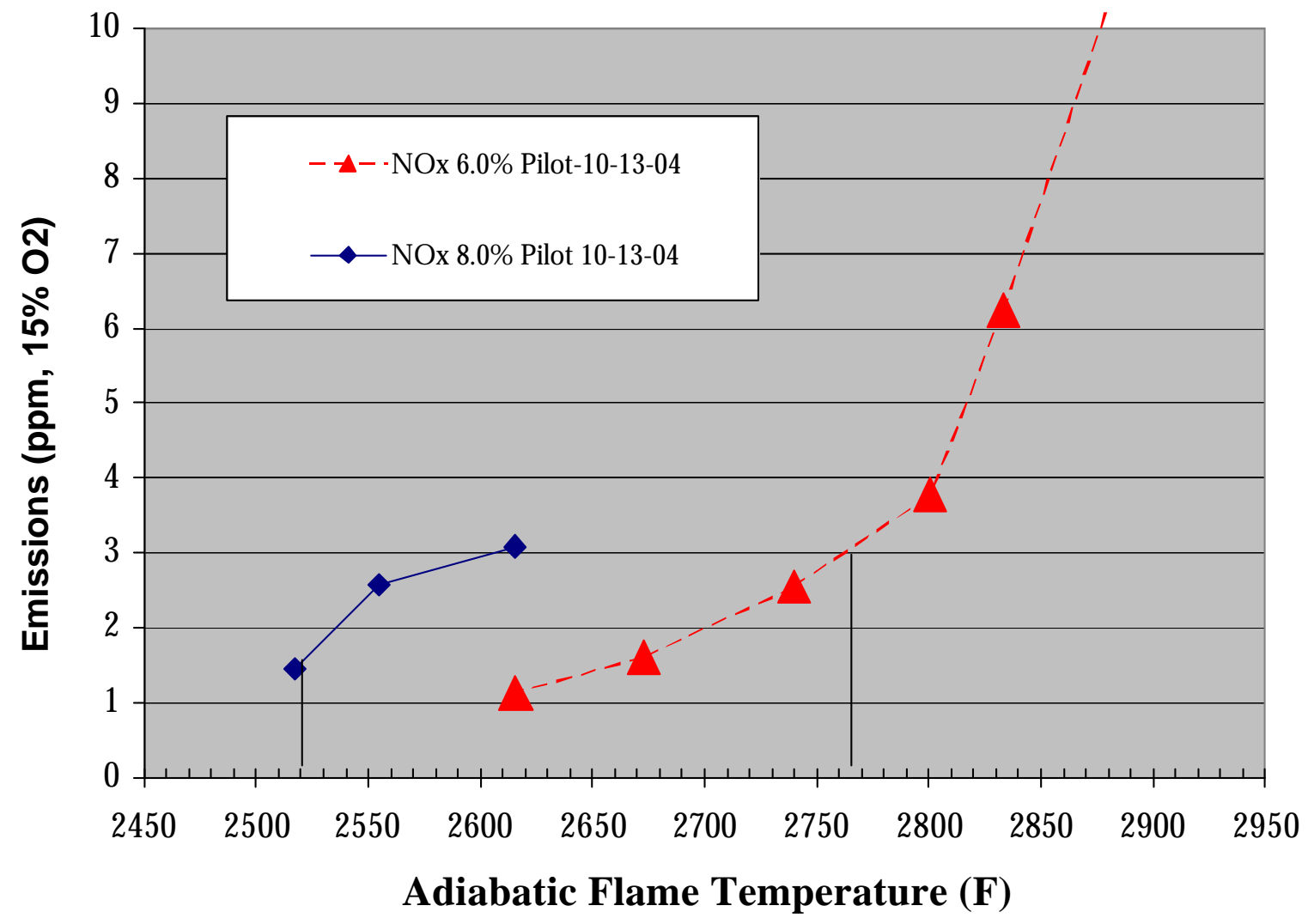

Figure 15 - T70 Piloted Module: 50\% Load Conditions

Figure 16 shows combustor pressure oscillation amplitudes for the unpiloted module at full load. While amplitudes are generally very low, there is evidence of rising amplitudes at higher Tad with pilot fueling below 4\%. Generally, oscillation amplitudes below 0.5 
psi are considered acceptable. On this basis, the amplitudes seen at lower pilot fueling rates (and higher Tad) would be considered excessive.

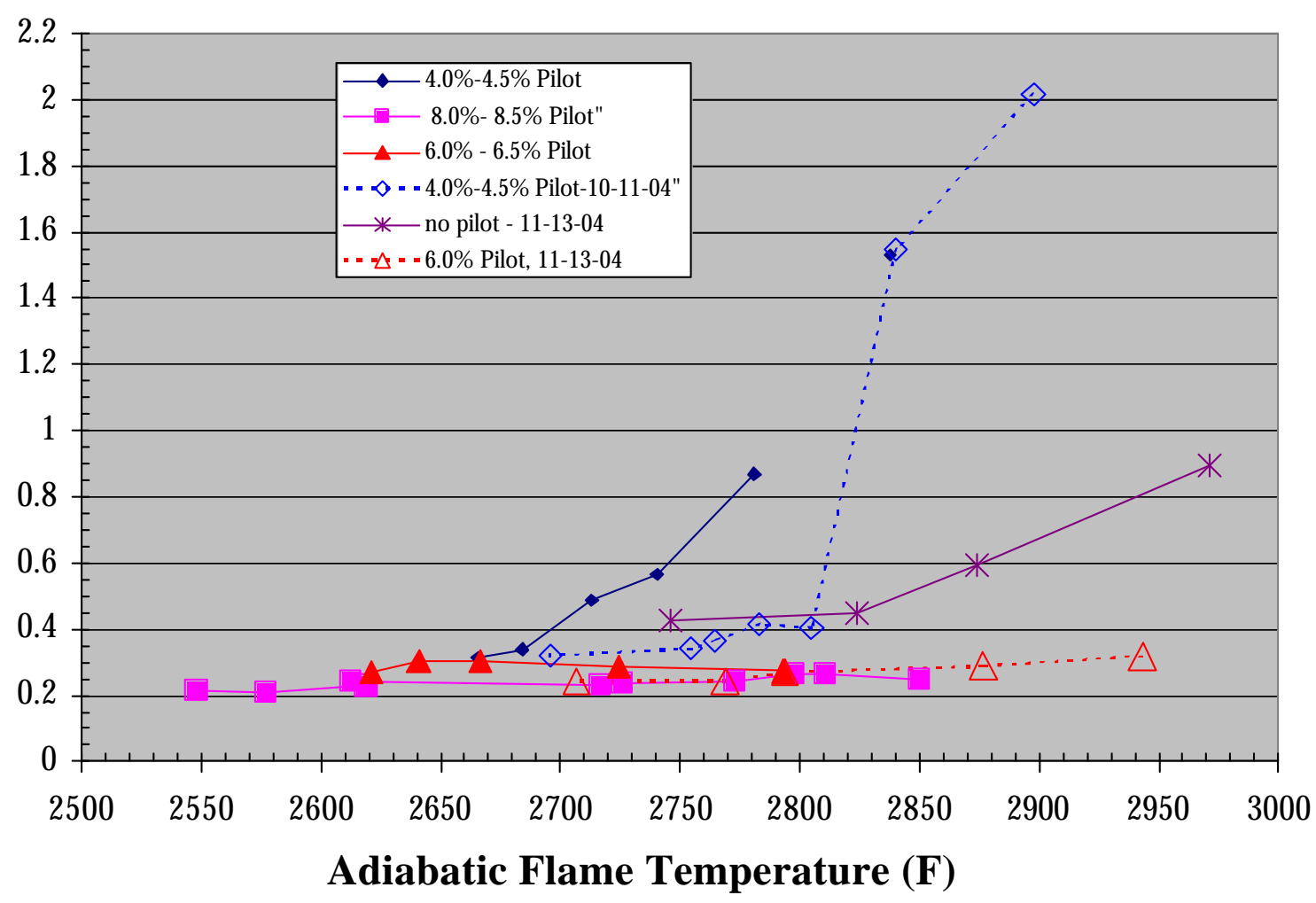

Figure 16 - T70 Piloted Module: Pressure Oscillations

Clearly, the occurrence of high amplitude pressure oscillations in the single module tests is a matter that requires further assessment. More detailed mapping is in order to more definitively characterize the acoustics of the piloted module. However, it should be noted that the gas turbine industry's understanding of combustor pressure oscillations is incomplete. We do know that the acoustic nature of the test rig plays as important a part in oscillations as does module/injector design. It is not unusual to see differences in the acoustic behavior of an injector in a single injector rig and in an engine. So while the absence of high amplitude oscillations in a rig is a positive sign, it is not a guarantee that 
oscillations will not occur in an engine. The opposite can also be true, with rig amplitudes exceeding levels observed in engine tests.

At this point in the RCL technology development, we are encouraged by the ability to operate the piloted module below 3 ppm NOx with low oscillation amplitudes at about $6 \%$ pilot fueling. Further rig tests and, ultimately, an engine test will be required to assess any oscillation issues that might arise in a commercial product. Based on the work to date, it appears that any high amplitude oscillations that occur would be tied more to pilot design than module design. Our experience with LP combustion suggests that there is a high likelihood that the pilot design could be optimized to reduce oscillation amplitudes in an engine if required.

Overall, the piloted module tests were a confirmation that the presence of the pilot injector does not significantly degrade module emissions with pilot fuel flow rates on the order of $6 \%$. This is somewhat higher but close to the levels of pilot fueling used in current LP combustion systems ( 2 to $4 \%$ ). Thus, we anticipate that the piloted RCL module will not add any mechanical or control complexity to a gas turbine product beyond what already is in place for current LP combustion systems.

\section{Saturn Testing}

\subsection{Saturn Combustor Configuration}

For the Saturn engine demonstration, four T70-sized modules were required. Three new modules were fabricated to supplement the one module already tested. The three new modules were similar to the original T70 module. The four modules and associated hardware are shown in Figs. 17 through 19. The modules were configured in a square array as shown in Fig. 18. 


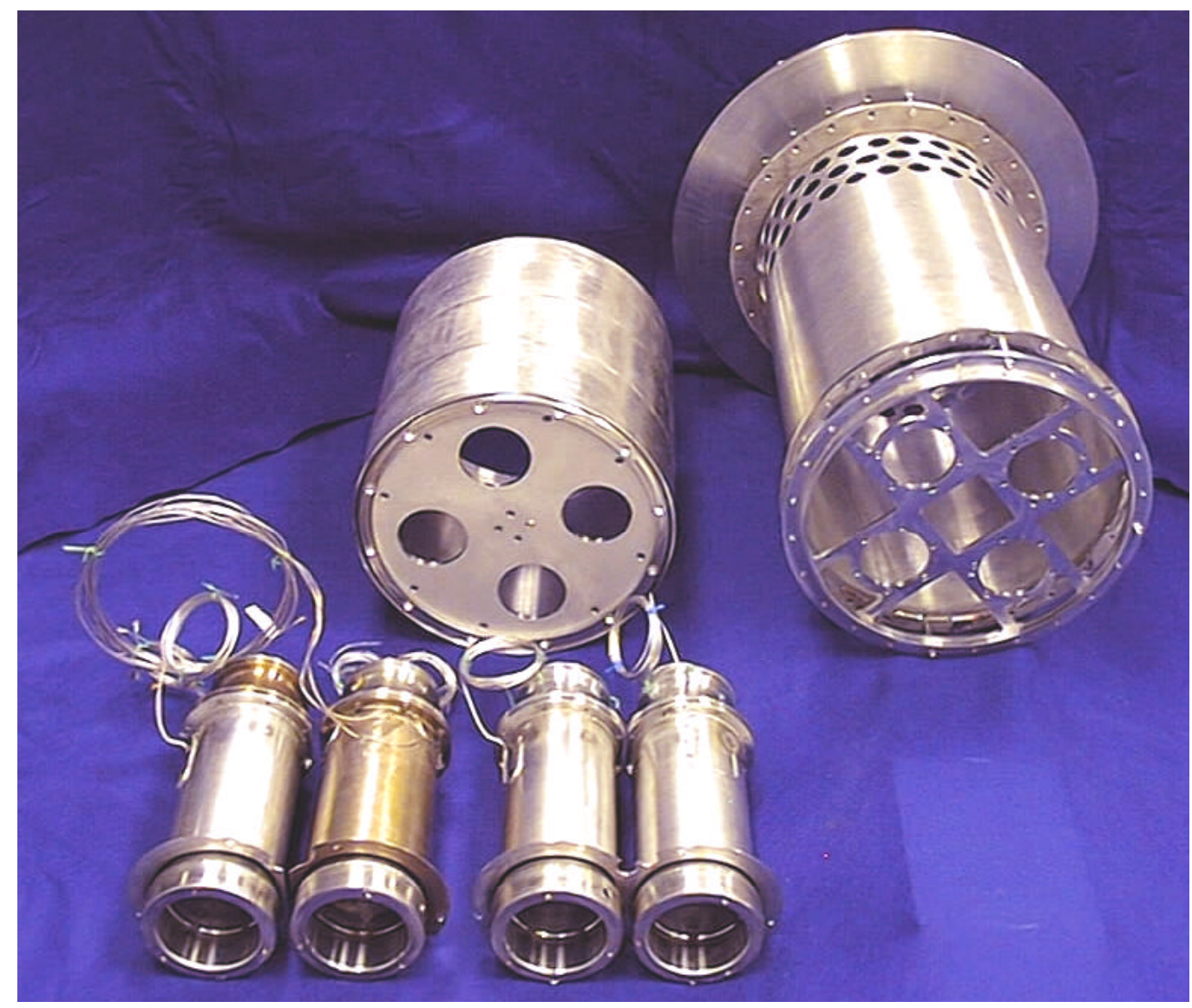

Figure 17 - Saturn RCL Combustor Hardware 


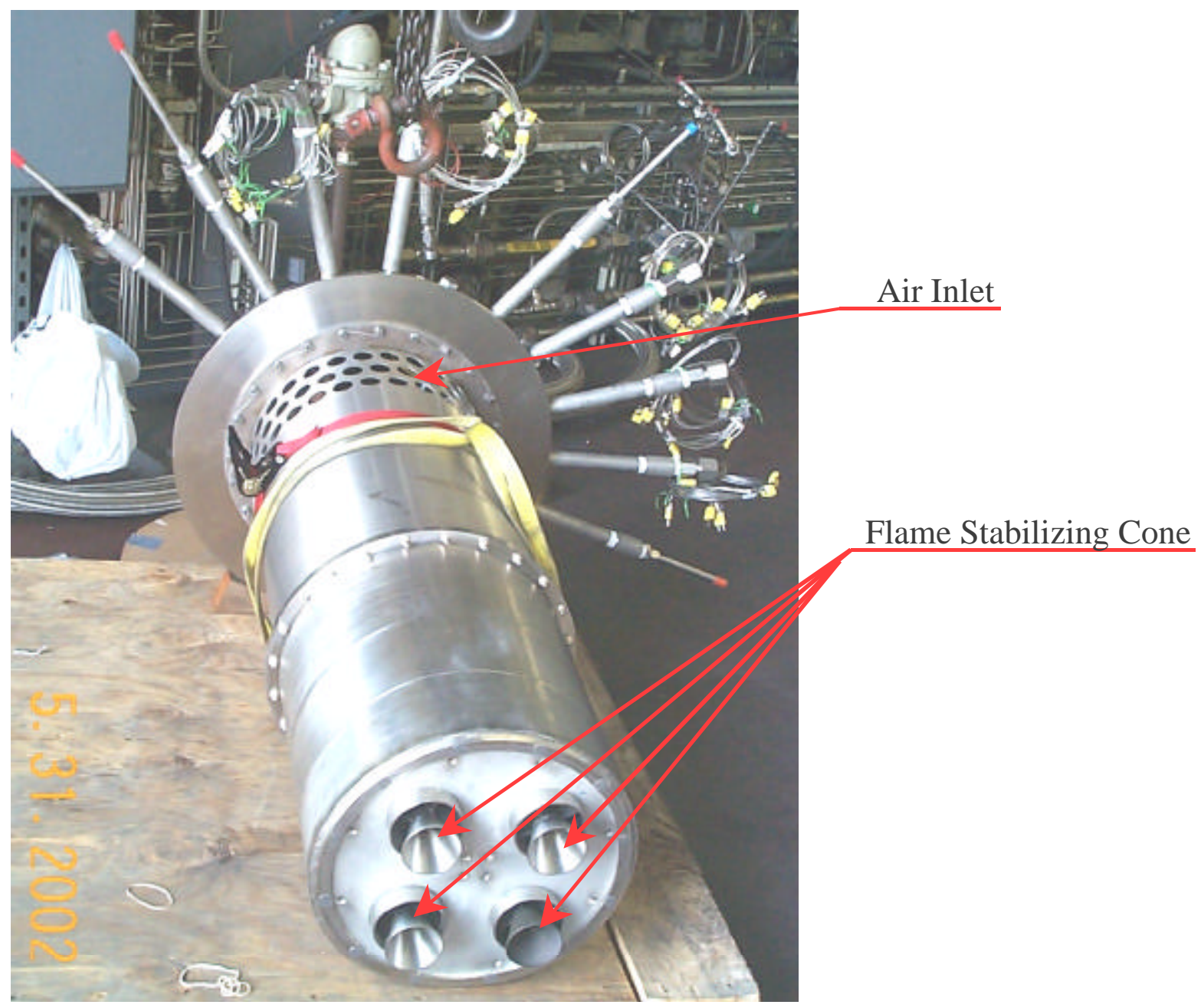

Figure 18 - Saturn RCL Combustor Assembly 


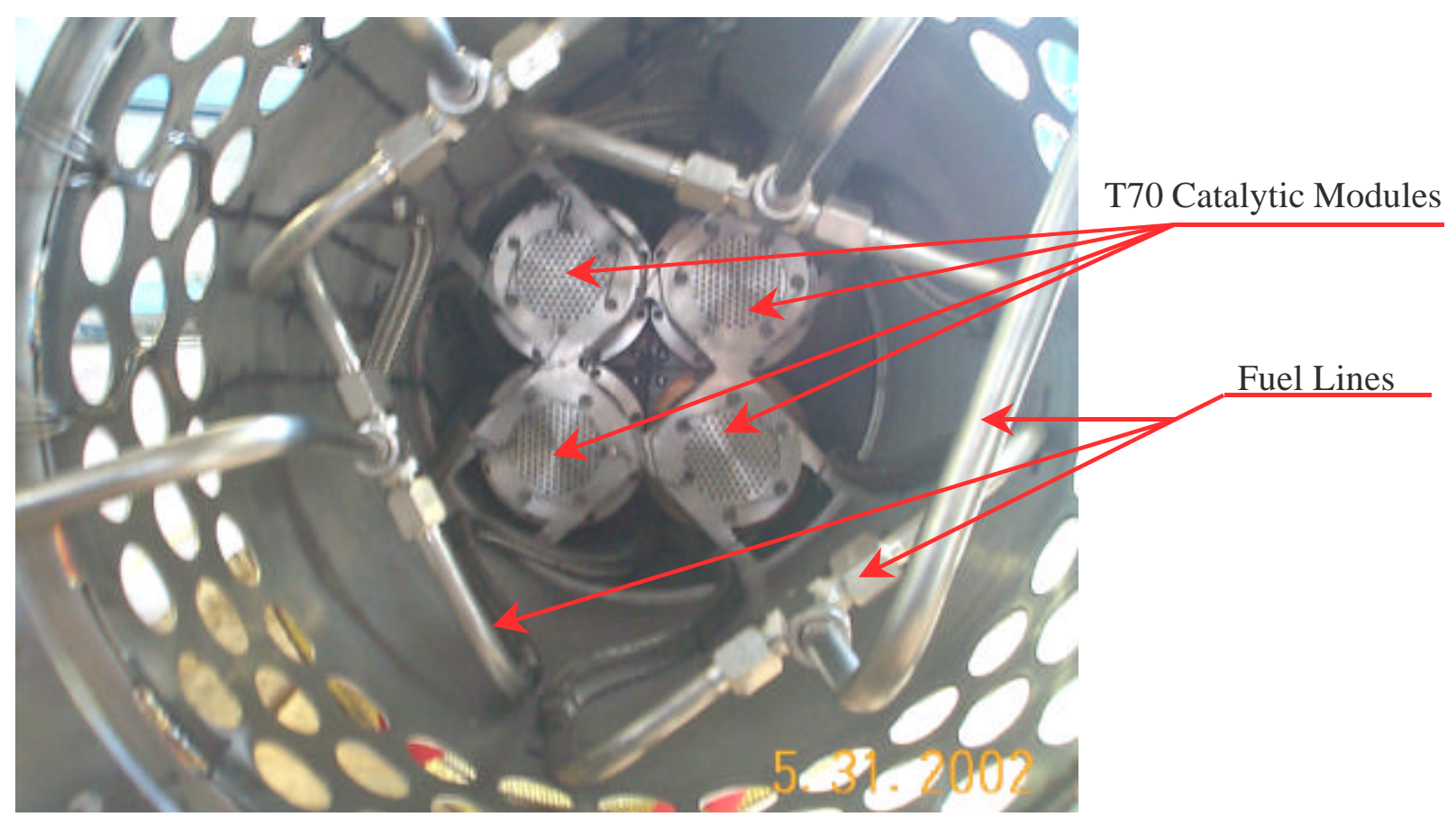

\section{Figure 19 - Saturn RCL Combustor Hardware Installed in Combustor Housing (View Forward Looking Aft)}

The module configuration was modified slightly for the Saturn tests. The conical flame stabilizer was moved upstream by $1.3 \mathrm{~cm}$ (0.5 inches). This increased the gas exit velocity from the module and reduced any possibility of flashback and/or flame anchoring within the post-mix zone. In addition, prior to the engine test, the air flow split of the modules was modified to optimize performance for the Saturn operating conditions.

Thermocouples were installed on all four reactors to monitor material temperatures during operation. Ports were provided for gas sampling both upstream and downstream of the reactors. 


\subsection{Single Module Testing at Saturn Conditions}

Prior to the Saturn engine test, testing was conducted on a single module at Saturn conditions in the high-pressure rig. The primary objective of the test was to document the emissions performance of the module at Saturn conditions.

The same combustor liner used for the T70 tests was used for the Saturn tests. However, to improve performance, dome cooling holes were sealed shut, internal air deflectors were used to direct dilution air flow directly downstream (preventing dilution air migration into the primary zone), and a thermal barrier coating was applied to the combustor.

Three Saturn operating points (100, 74, and 57\% load) were selected for single-injector tests (Table 3).

Table 3. Nominal Saturn-Engine Combustor Inlet Conditions

\begin{tabular}{|l|c|c|c||}
\hline $\begin{array}{l}\text { Saturn-engine combustor inlet } \\
\text { conditions }\end{array}$ & $\mathbf{5 7 \%}$ load & $\mathbf{7 4 \%}$ load & $\mathbf{1 0 0 \%}$ load \\
\hline \hline Temperature & $215 \mathrm{C} / 415 \mathrm{~F}$ & $225 \mathrm{C} / 440 \mathrm{~F}$ & $250 \mathrm{C} / 485 \mathrm{~F}$ \\
\hline Pressure (atm) & 4.85 & 5.41 & 6.15 \\
\hline
\end{tabular}

As the Saturn combustor inlet temperature is below the catalyst lightoff temperature (but above the catalyst extinction temperature) the test procedure included a catalyst lightoff transient wherein the rig inlet temperature was increased to about $360 \mathrm{C}(680 \mathrm{~F})$. Catalyst lightoff was performed at Saturn full-load flow and pressure. The rig inlet temperature was then decreased to the Saturn 100\% load temperature (250 C / 485 F). The reactor remained lit at this condition and at temperatures as low as $215 \mathrm{C}(415 \mathrm{~F})$. 
For each Saturn operating point tested, desired rig conditions (flow rates, pressure, andtemperature) were established and then emissions data taken at various fuel flows. At selected points, fuel/air ratio was directly measured in the post-mix duct using gas sample extraction and GC analysis.

Single module rig emissions at Saturn conditions are shown in Figs 20 and 21. In general, NOx emissions below 3 ppm were achievable with $\mathrm{CO}$ below $10 \mathrm{ppm}$ at the three load points tested. Figure 20 shows NOx and CO emissions at Saturn full-load conditions. NOx emissions dropped below 3ppm at a Tad of about 1688C (3070F). CO levels were below $10 \mathrm{ppm}$. CO emissions remained low until lean blowout occurred at less than 1615C (2940F). Part load emissions data (74\% and 57\% load) are shown in Fig. 21. Emissions are very similar to the full load data.

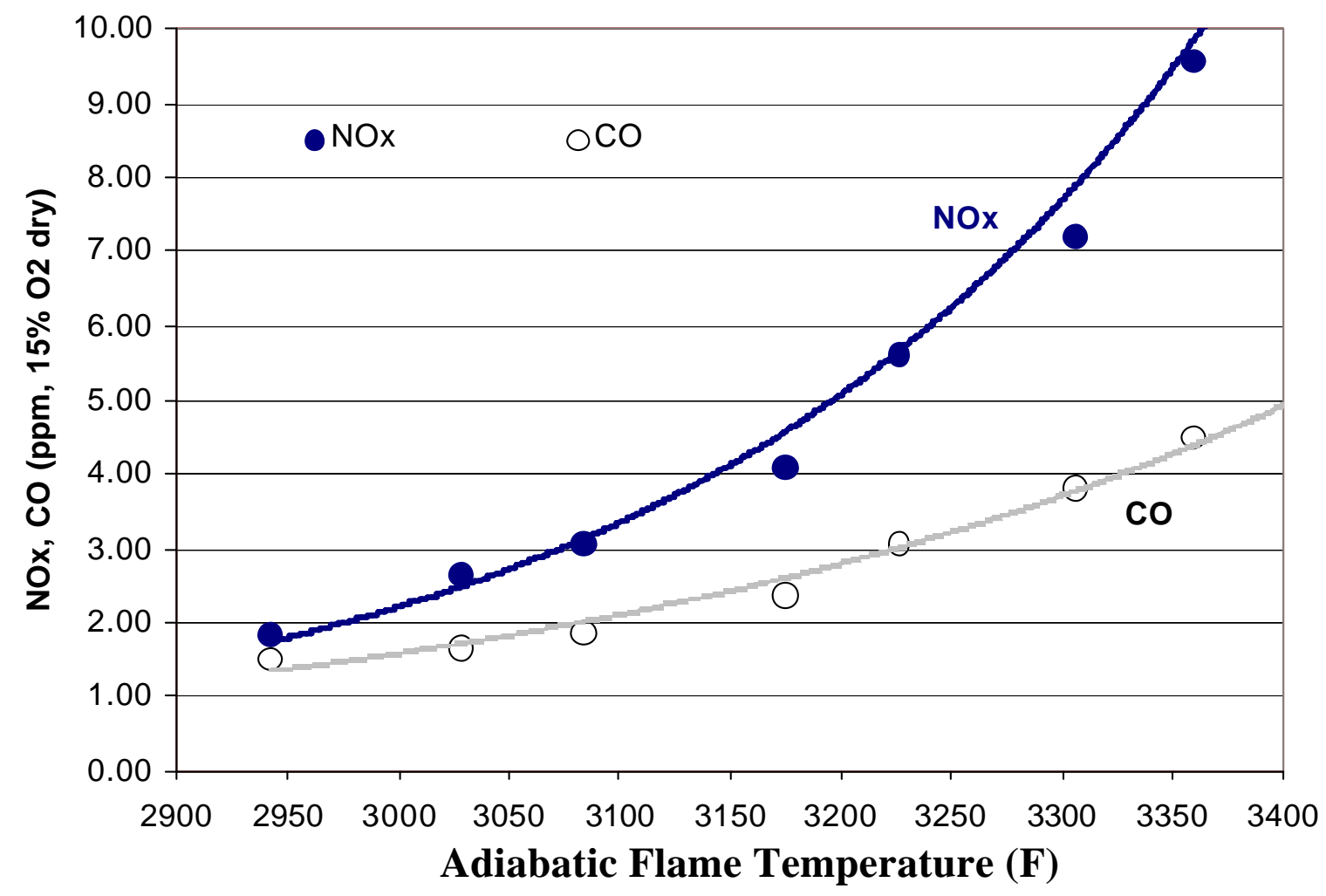

Figure 20 - NOx and CO Emissions at Saturn Full-Load Conditions 


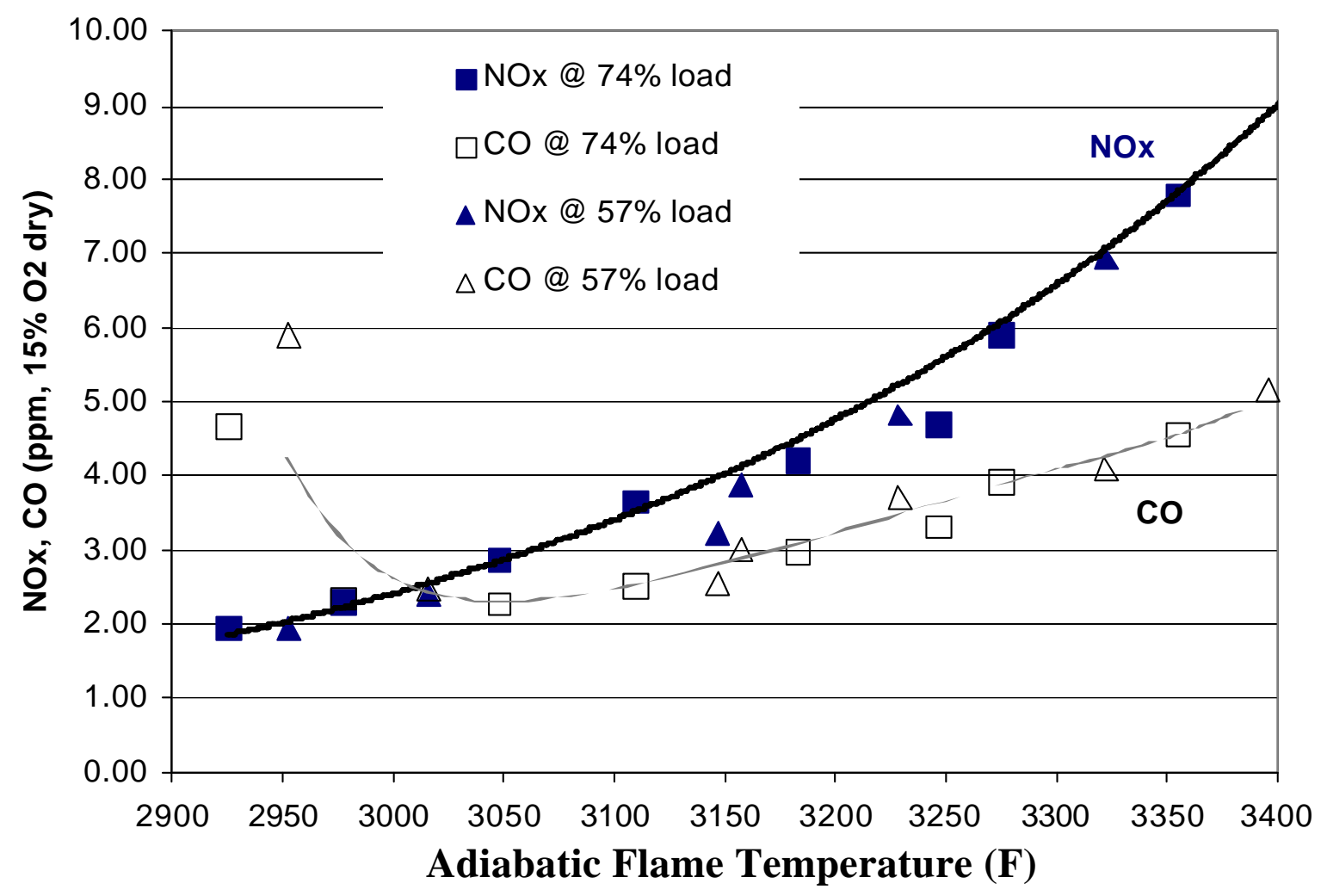

Figure 21 - Single Saturn Module Emissions: Part Load Conditions 
During the first module tests at Saturn conditions, the combustion system pressure drop was $10 \%$, very high for a gas turbine system. The high pressure drop was a result of using the T70 module (with a design pressure drop of $4 \%$ ) at Saturn conditions.

To reduce the module pressure drop, the module air flow split was modified to decrease the reactor flow. This lowered the pressure drop to approximately 7\%, a more realistic figure (although still high) for an industrial turbine. The modification resulted in a slightly richer reactor design point. Subsequently, a test of the modified module was conducted at Saturn full load conditions. The emissions data from this test are shown in Fig. 22. Emissions are essentially unchanged. Thus, the module configuration yielding $7 \%$ pressure drop was adopted for the actual engine test.

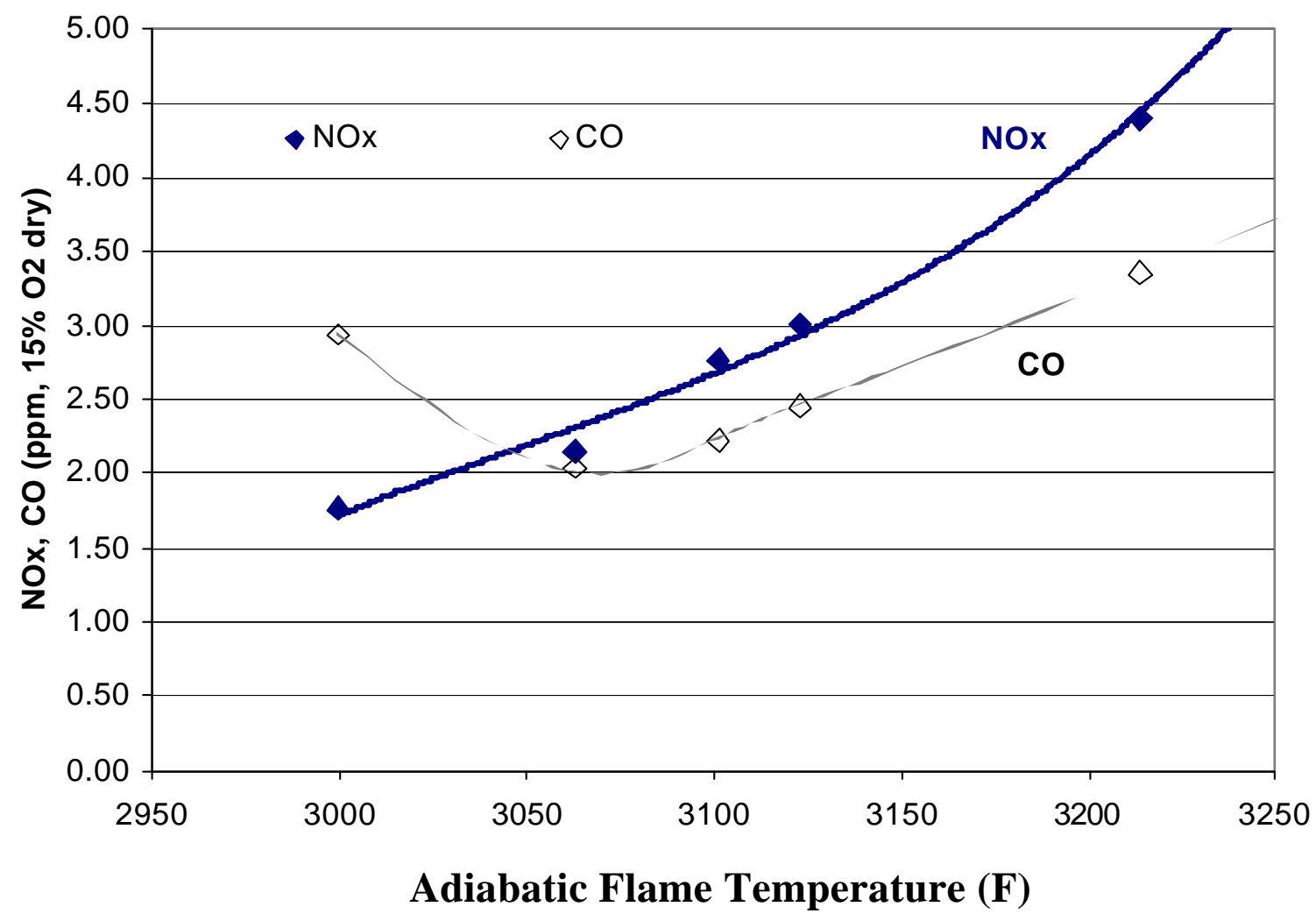

\section{Figure 22 - Single Saturn Module Emissions: Full Load Conditions with Modified Air Flow Split}




\subsection{Saturn Engine Demonstration}

Following the single module rig tests, the set of four modules was installed in the single can combustor of the Saturn engine. The primary goal of the engine tests was to assess RCL transient performance. The engine test also provided a limited opportunity to assess module robustness in an engine environment. Emissions during transients were not of concern, but steady-state emissions data were obtained.

Engine start-up data and a description of the start-up procedure are presented in Fig. 23. During engine cold crank conditions, 0 to $29 \%$ gas producer speed (Ngp), the rig preburner was ignited and adjusted to $260 \mathrm{C}(500 \mathrm{~F})$ outlet temperature, below the catalyst light-off temperature. The small preburner fuel flow provided negligible increase in engine speed. Once at $29 \% \mathrm{Ngp}$, fuel was introduced to the modules (which were still inactive) and combustion was initiated in the lean combustor using a torch igniter. With the starter motor still engaged, fuel flow was ramped up and the engine accelerated to $65 \%$ Ngp. At $65 \%$ Ngp the starter motor disengaged and engine operation was selfsustaining. Preburner outlet temperature remained at $260 \mathrm{C}(500 \mathrm{~F})$, and the reactors remained inactive. 


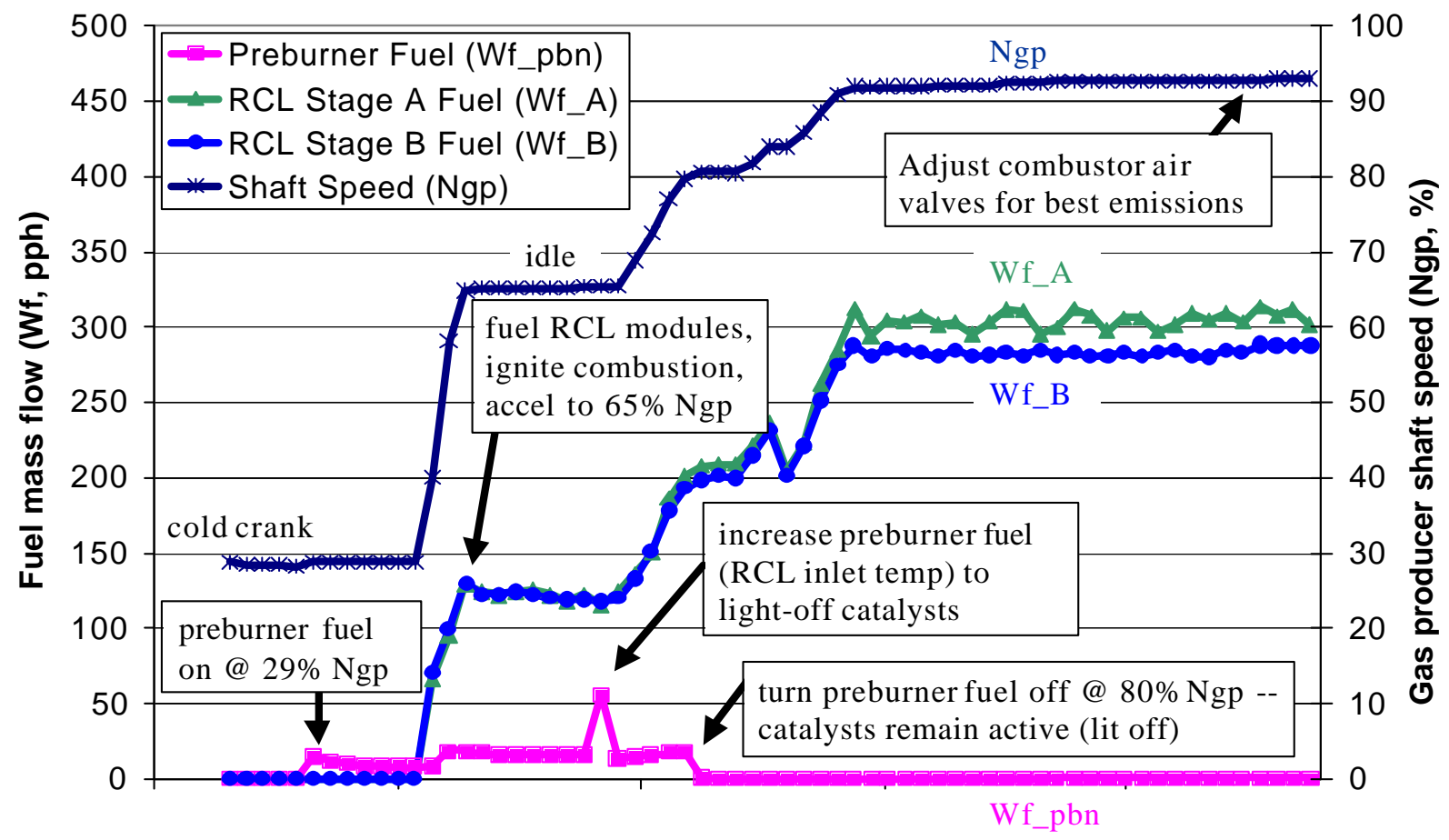

Time

\section{Figure 23 - Saturn Engine Parameters During Engine Light-Off}

Preburner temperature was then increased to about $350 \mathrm{C}(660 \mathrm{~F})$ to initiate module lightoff. Engine speed was increased to $80 \% \mathrm{Ngp}$, the preburner was turned off, and the catalysts remained active. Engine speed was then increased to approximately $93 \%$ and the variable airflow valves were adjusted to obtain optimum emissions. The valves controlled the airflow to the modules thus allowing control of NOx and CO emissions. Emissions data were then taken as engine speed was reduced in increments of about $1 \%$ Ngp. The airflow split into the combustion rig was adjusted for minimum emissions at each speed.

Surface temperatures of the four reactors were recorded during engine start. These data are shown in Fig. 24 as functions of time. It is hypothesized that the small time increments between the light-off of the four modules were due to non-uniform transient heating of the reactors. After light-off, the surface temperatures of all four modules were 
uniform and remained between $515 \mathrm{C}(960 \mathrm{~F})$ and $533 \mathrm{C}(992 \mathrm{~F})$, well below the allowable temperature of $760 \mathrm{C}(1400 \mathrm{~F})$.

Saturn engine emissions are shown in Fig. 25. Over a low emissions operating range of 82 to $89.7 \% \mathrm{Ngp}$ (32\% to $61 \%$ load), NOx emissions did not exceed $3 \mathrm{ppm}$ and averaged $2.1 \mathrm{ppm}$ with less than $10 \mathrm{ppm} \mathrm{CO}$. Over this same range, UHC emissions remained below 3 ppm. Combustor pressure oscillations were acceptably low, below $0.7 \mathrm{kPa}(0.1$ psi) peak-to-peak. GC analyses of gas samples from each of the four modules showed little fuel/air ratio variation among the modules. 


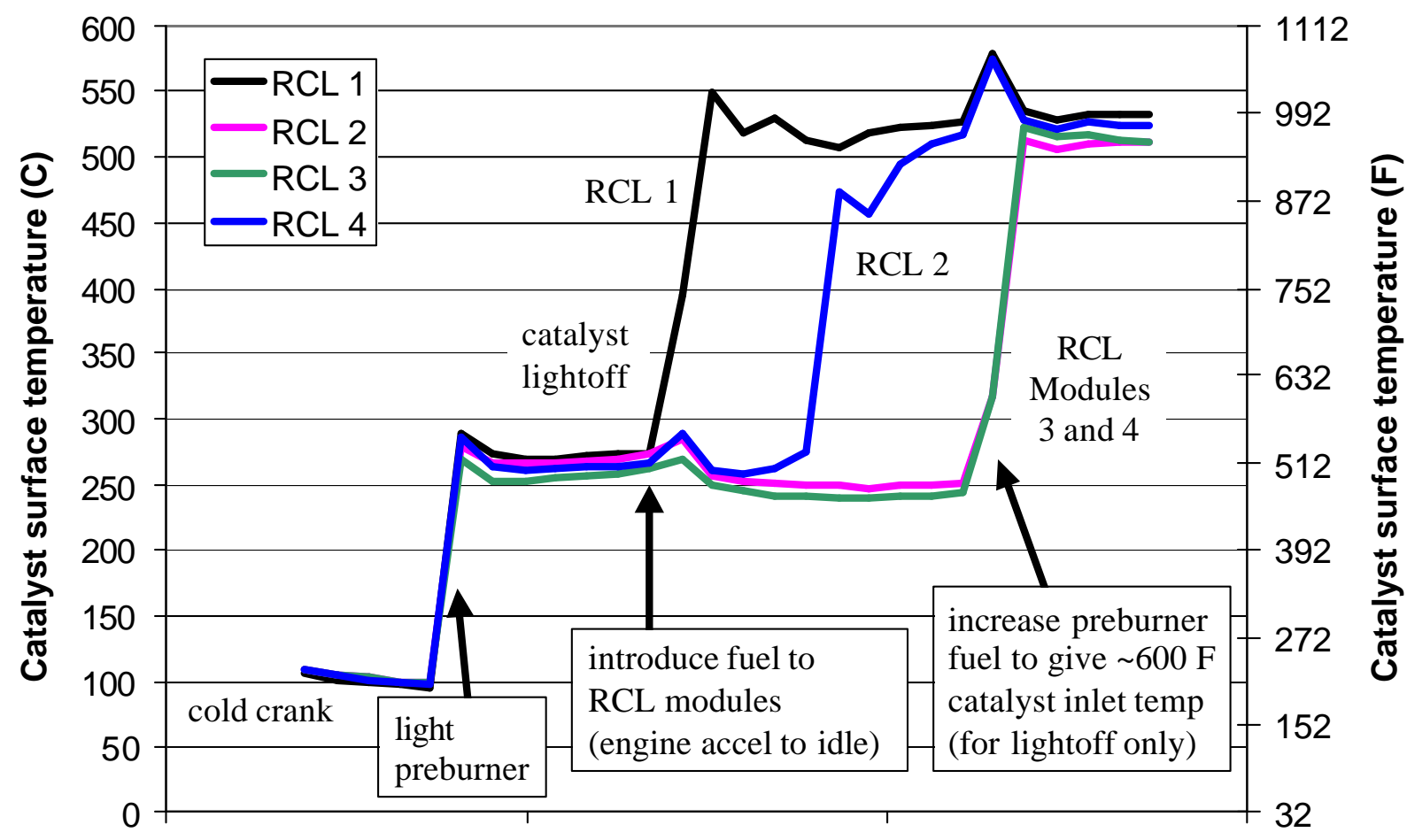

Time

Figure 24 - Catalytic Reactor Surface Temperatures During Saturn Engine Light-Off 


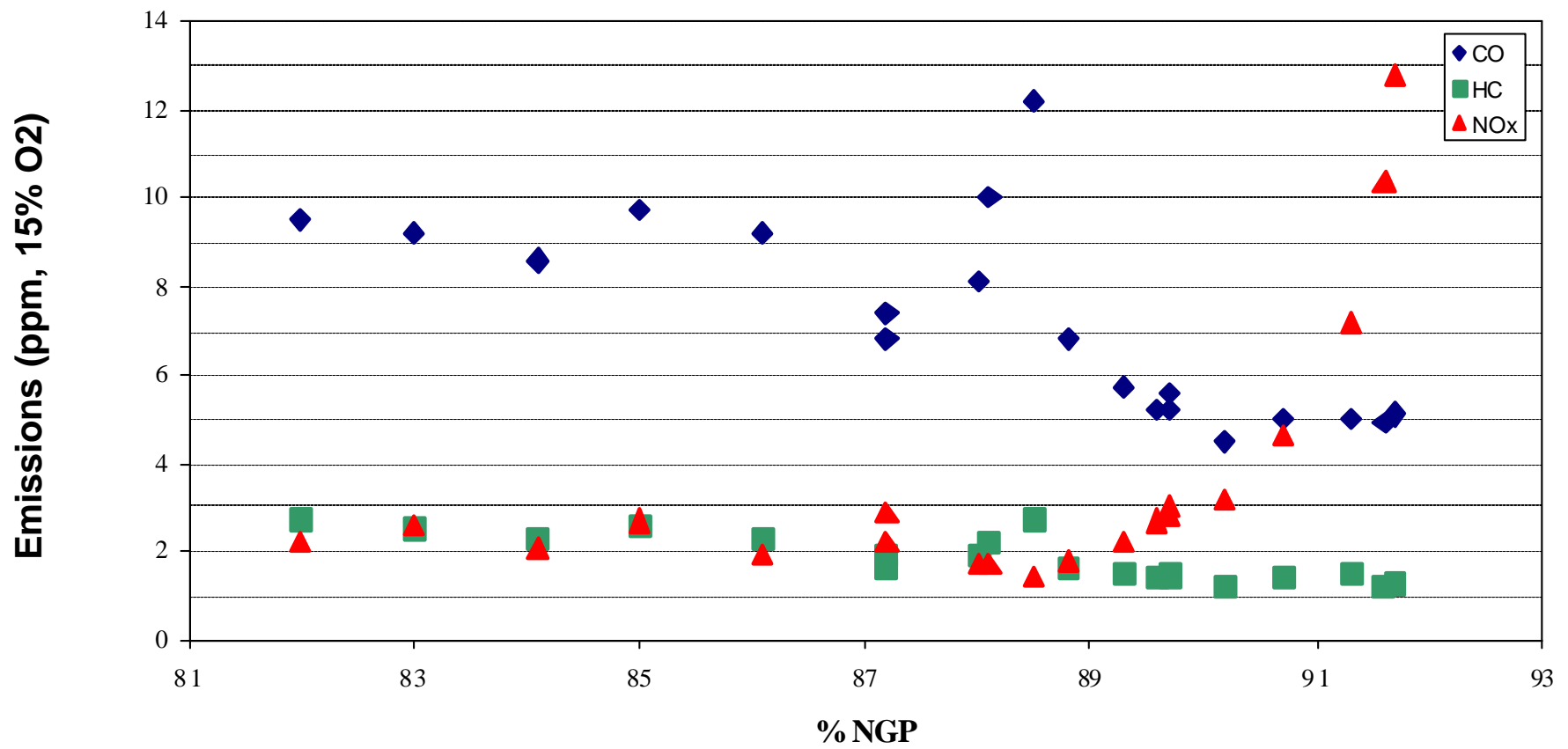

Figure 25 - Saturn Engine Emissions

At $89 \% \mathrm{Ngp}$, combustor inlet air conditions were $0.5 \mathrm{MPa}(5.0 \mathrm{~atm})$ and $223 \mathrm{C}$ (434 F). At $82 \% \mathrm{Ngp}$, combustor inlet conditions dropped to $0.39 \mathrm{MPa}$ (3.9 atm) and $191 \mathrm{C}$ (376 F). For all data points shown in Fig. 25 the preburner was turned off. The catalyst remained active at normal Saturn compressor discharge temperatures (as low as $191 \mathrm{C} /$ $376 \mathrm{~F})$.

Table 4 summarizes the Saturn engine operating data at the low-end and high-end of the low emissions operating range. In general, the steady state test results show good combustor performance (low emissions and pressure oscillations) . More importantly, the Saturn engine demonstration shows the feasibility of engine start-up, acceleration, and operation using RCL combustion with simple engine controls and without data input from the module instrumentation. 
Table 4. Saturn Operating Data at Low and High-End of Achievable Operating Range.

\begin{tabular}{|c|c|c|}
\hline Parameter & Max Condition & Min Condition \\
\hline Output (kW) & 453 & 237 \\
\hline Nominal Load (\%) & 61 & 32 \\
\hline $\begin{array}{c}\text { Combustor inlet } \\
\text { Pressure (atm) }\end{array}$ & 5.0 & 3.9 \\
\hline $\begin{array}{c}\text { Combustor inlet } \\
\text { temperature (F) }\end{array}$ & 434 & 376 \\
\hline $\begin{array}{c}\text { NOx emissions } \\
\text { (ppm; 15\% O2) }\end{array}$ & 2.2 & 2.2 \\
\hline $\begin{array}{c}\text { CO emissions } \\
\text { (ppm; 15\% O2) }\end{array}$ & 5.7 & 9.5 \\
\hline $\begin{array}{c}\text { Combustor pressure } \\
\text { oscillations } \\
\text { (kPa; peak-to-peak) }\end{array}$ & 0.7 & 0.7 \\
\hline
\end{tabular}

The maximum engine speed achieved was limited to $92.9 \%$ due to high ducting temperatures just upstream of the turbine section. The high temperatures occurred because of inadequate mixing in the combustion dilution zone downstream of the modules. At this maximum speed, a high quantity of air was being diverted from the modules to the dilution zone in an attempt to lower the duct temperatures. As a result, the combustor primary zone was running hotter than desired and NOx emissions exceeded $3 \mathrm{ppm}$. Engine operation with low emissions was limited to speeds below $89.7 \%$

At the other end of the low emissions operating range ( $82 \%$ speed), the compressor bleed valve was opened to prevent compressor surge. With the bleed valve open, there was insufficient air to maintain the combustor in a low emissions mode and NOx emissions again exceeded the 3 ppm level. 


\section{Conclusions}

The Taurus 70 high pressure tests (single module) and the Saturn engine tests (four modules) have shown that with proper design, the rich catalytic technology can achieve NOx emissions levels below 3 ppm with low $\mathrm{CO}$ emissions at typical gas turbine operating conditions.

A number of other beneficial characteristics of the technology have also been demonstrated:

Low catalyst light off temperature as compared to a lean catalytic system.

Reactor material temperatures that are relatively insensitive to the reactor fuel-air ratio. This provides a wide range of safe operation.

> Comparable module size to current LP injectors, reducing the engine modifications needed for technology integration.

Low amplitude combustor pressure oscillations.

Very low reactor extinction temperatures. Below $149 \mathrm{C}$ (300 F). The reactor remains active at temperatures below the ignition temperature, widening the engine load range over which low emissions can be achieved.

\section{Recommendations}

Based on the positive results of this program the following steps are recommended:

- Evolve the present module design to engine prototype status for the Taurus 70. The module should retain the central pilot to enable engine startup and enhance transient stability.

- Validate the prototype module design through additional single module rig tests at Taurus 70 conditions. 
- Upon successful completion of the single module tests, fabricate a full set of Taurus 70 modules (up to 12 modules required for engine operation) and conduct in-house engine tests to document performance.

- Evaluate the service life of the catalytic module and demonstrate product readiness through a twelve-month field trial of a Taurus 70 engine. 